\title{
Habitual exercise plus dietary supplementation with milk fat globule membrane improves muscle function deficits via neuromuscular development in senescence-accelerated mice
}

\author{
Satoshi Haramizu, Takuya Mori, Michiko Yano, Noriyasu Ota, Kohjiro Hashizume, Atsuko Otsuka, Tadashi Hase \\ and Akira Shimotoyodome*
}

\begin{abstract}
We examined the effects of habitual exercise plus nutritional intervention through consumption of milk fat globule membrane (MFGM), a milk component, on aging-related deficits in muscle mass and function in senescence-accelerated P1 mice. Combining wheel-running and MFGM (MFGMEx) intake significantly attenuated age-related declines in quadriceps muscle mass (control: $318 \pm 6$ mg; MFGMEx: $356 \pm 9$ mg; $P<0.05$ ) and in contractile force (1.4-fold and 1.5 -fold higher in the soleus and extensor digitorum longus muscles, respectively). Microarray analysis of genes in the quadriceps muscle revealed that MFGMEx stimulated neuromuscular development; this was supported by significantly increased docking protein-7 (Dok-7) and myogenin mRNA expression. Treatment of differentiating myoblasts with MFGM-derived phospholipid or sphingolipid fractions plus mechanical stretching also significantly increased Dok-7 mRNA expression. These findings suggest that habitual exercise plus dietary MFGM improves muscle function deficits through neuromuscular development, and that phospholipid and sphingolipid in MFGM contribute to its physiological actions.
\end{abstract}

Keywords: Aging; Milk fat globule membrane; Muscle function; Neuromuscular junction

\section{Background}

Aging skeletal muscle is characterized by progressive loss of muscle mass and function (Breen and Phillips 2011). This age-related deficit, known as sarcopenia, has a profound effect on quality of life in the elderly and increases the risk of morbidity, disability, and death (Janssen et al. 2004). Despite the high prevalence and clinical relevance of sarcopenia, the exact biochemical and molecular mechanisms of muscle wasting during aging are not fully understood. The etiology of sarcopenia is multi-factorial and involves both intrinsic and extrinsic factors (SinhaHikim et al. 2013; Tan et al. 2012).

Accumulated evidence from both animal and human studies suggests that skeletal muscle aging is strongly associated with degeneration of motor neurons, followed by changes in the structural and functional integrity of

\footnotetext{
* Correspondence: shimotoyodome.akira@kao.co.jp

Biological Science Laboratories, Kao Corporation, Tochigi, Japan
}

the neuromuscular junction (NMJ), along with functional denervation, and loss of motor units (Chai et al. 2011; Manini and Clark 2012; Valdez et al. 2010). Aging muscle fibers undergo denervation and reinnervation cycles that lead to remodeling of the motor units (Larsson 1995). Preferential denervation of the fast-twitch fibers and reinnervation by axonal sprouting from slow motor neurons result in the conversion of type II fast fibers to type I slow fibers (Balice-Gordon 1997; Kadhiresan et al. 1996). When denervation outpaces reinnervation, some of the muscle fibers degenerate and atrophy occurs in the remaining fibers (Rowan et al. 2012). Functional loss of NMJs and muscle mass ultimately contributes to compromised contractile function.

Milk is the main source of nutrition in newborn mammals. Recent findings in young adults have demonstrated that consumption of whole milk after resistance training can promote muscle protein synthesis and inhibit protein breakdown, leading to improved net muscle protein 
balance (Elliot et al. 2006; Josse et al. 2010; Wilkinson et al. 2007). In addition, milk protein has beneficial effects including suppressing postprandial glycemia and promoting changes in body composition for metabolic health (McGregor and Poppitt 2013). Milk contains approximately $3 \%$ to $5 \%$ fat, which is distributed in the form of tiny, spherical droplets or globules stabilized in the form of an emulsion. The diameter of the fat globule ranges from 0.2 to $15 \mu \mathrm{m}$, with an average of about $4 \mu \mathrm{m}$. The triglyceride core of the fat globules in milk is surrounded by a thin membrane called the milk fat globule membrane (MFGM). This membrane, which is about 10 to $20 \mathrm{~nm}$ in cross-section, acts as an emulsifier and protects the globules from coalescence and enzymatic degradation. The MFGM contains unique polar lipids and membrane-specific proteins (Cavaletto et al. 2008). The polar lipids in milk, which consist of phospholipids and sphingolipids, are located mainly (60\% to $70 \%)$ in the MFGM. Sphingolipids (highly bioactive molecules present mainly in polar lipids of animal origin) account for up to one third of the MFGM polar lipid fraction. Oshida et al. have shown that dietary sphingomyelin contributes to myelination in the central nervous system of developing rats (Oshida et al. 2003). Loss of myelinated nerve fibers, along with several abnormalities involving myelinated fibers, such as demyelination and myelin balloon figures, has been observed in elderly subjects. Deterioration of the myelin sheaths during aging may affect the functional properties of the peripheral nervous system; it may cause a decline in the conduction velocity of motor neurons and thereby in muscle strength and mass. Even though scientific evidence on the nutritional benefits of MFGM proteins and sphingolipids is accumulating (Vesper et al. 1999), the nutritional aspects and physiological functions of MFGM have not been fully investigated.

The senescence-accelerated mouse (SAM) exhibits several accelerated aging characteristics and is widely used in research on aging (Takeda et al. 1981). The SAM consists of two types of strain, namely the senescence-accelerated prone mouse (SAMP) and the senescence-accelerated resistant mouse (SAMR). Compared with SAMR strains, which are used as controls that age normally, SAMP strains show rapid progression of senescence, higher oxidative stress, decreased behavioral activity, and a shorter median life span (Takeda et al. 1991, 1997; Takeda 1999; Hosokawa 2002). These characteristics observed in SAMP strains are similar to those observed in humans with normal aging; therefore, SAMP strains are useful models of human aging. SAMP strains might also be useful for studying muscle aging. Sakakima et al. (2004) demonstrated that sarcopenia and age-associated morphologic changes in the leg muscles occur earlier in SAMP1 mice than in normal ICR mice. Derave et al. (2005) reported reduced muscle mass, selective type-II fiber atrophy, and reduced contraction speed in the soleus muscle of SAMP8 mice. There is, thus, support for using this model to study skeletal muscle aging.

Our previous studies have shown that dietary green tea extract (GTE) plus habitual exercise improves skeletal muscle function and metabolism in mice, including in SAMP1 mice (Murase et al. 2005, 2006a, b, 2008; Shimotoyodome et al. 2005). These findings led us to investigate whether, and how, habitual exercise plus nutritional intervention improves skeletal muscular physiology.

Here, we investigated whether long-term consumption of MFGM proteins and lipids combined with habitual exercise could prevent age-related deficits in muscle mass and function. In light of our finding that a combination of dietary supplementation with MFGM and voluntary wheel-running prevented age-related declines in skeletal muscle mass and strength in SAMP1, we also attempted to elucidate the mechanisms underlying these improvements after long-term MFGM consumption.

\section{Methods \\ Materials}

MFGM was purchased from MEGGLE Japan Co. Ltd (Tokyo, Japan). The composition of the MFGM was $43.8 \%$ protein, $37.1 \%$ fat, $10.3 \%$ carbohydrate, $13.6 \%$ lactose, $16.6 \%$ phospholipids (4.71\% phosphatidylcholine, 5.2\% phosphatidylethanolamine, $1.32 \%$ phosphatidylinositol, $1.74 \%$ phosphatidylserine, 3.0\% sphingomyelin, and others), $4.3 \%$ ash, $2.4 \%$ minerals, $4.5 \%$ moisture, and $1.9 \%$ others. The composition of the fatty acids was $31.6 \% \mathrm{C} 18: 1,23.8 \% \mathrm{C} 16: 0$, 12.9\% C18:0, 7.5\% C14:0, 4.3\% C18:2(n-6), 2.1\% C12:0, 1.6\% C4:0, 1.6\% C10:0, 1.5\% C16:1, 1.2\% C6:0, and $<1.0 \%$ others. The content (all in g/100 g) of glutamic acid was 8.44, of leucine 4.46, aspartic acid 3.82, lysine 3.69, proline 3.49 , serine 2.83 , valine 2.54 , threonine 2.33 , isoleucine 2.26 , phenylalanine 2.1 , tyrosine 1.86 , arginine 1.85 , alanine 1.66 , histidine 1.35 , methionine 1.16 , glycine 1.04 , tryptophan 0.71 , and cysteine 0.57 . Milk-derived sphingomyelin was purchased from NOF Corporation (Tokyo, Japan). Phospholipid and sphingolipid fractions were also prepared from MFGM. In brief, the MFGM was homogenized in an ice-cold chloroform-methanol mixture (2:1) by using a homogenizer (TK autohomomixer; Tokusyukika Kogyo Co. Ltd., Osaka, Japan). The soluble fraction obtained was subjected to acetone precipitation to separate the polar lipids. The phospholipid fraction (PLF) was then purified by using column chromatography over silica gel (Yamazen Hi-Flash silica gel column; Yamazen Corp., Osaka, Japan). Phosphatidylcholine, phosphatidylethanolamine, phosphatidylserine, glucosylceramide, and lactosylceramide in the purified PLF were detected by using thin-layer chromatography (TLC) analysis (chloroformmethanol-water; 65:16:2). After alkaline hydrolysis, the sphingolipid fraction (SLF) was obtained as an acetone- 
insoluble fraction after acetone precipitation. Glucosylceramide, lactosylceramide, and sphingomyelin were detected by TLC analysis of the SLF. Quantitative analysis by using high-performance liquid chromatography revealed that the SLF was $52 \%$ sphingomyelin. GTE was prepared and analyzed as described previously (Haramizu et al. 2011a, 2011b). The total polyphenol (catechin) content of the GTE was $81 \%$, and the caffeine content was $0.1 \%$. The polyphenols were made up of epigallocatechin gallate (41\%), epigallocatechin (23\%), epicatechin gallate (12\%), epicatechin (9\%), gallocatechin (7\%), gallocatechin gallate (4\%) and others (4\%).

\section{Animals and experimental design}

SAMP1 exhibit several characteristics of accelerated aging and are widely used in aging research (Sakakima et al. 2004). ICR mice are widely used as a control strain in experiments on SAMP1 (Lee et al. 2013; Nagano et al. 2000). Male 15-week-old SAMP1 and ICR mice were purchased from Japan SLC, Inc. (Hamamatsu, Japan) and maintained under controlled conditions of temperature $\left(23 \pm 2^{\circ} \mathrm{C}\right)$, humidity $(55 \% \pm 10 \%)$, and lighting (0700 to $1900 \mathrm{~h}$ ). The mice were fed a laboratory chow (CE-2, CLEA Japan, Inc., Tokyo, Japan) and had free access to drinking water to acclimate to the housing conditions for 2 months. At the age of $23 \mathrm{wk}$, all mice were weighed and those that were self-injurious (i.e., those with visible injury) were removed from the study. SAMP1 and ICR mice whose body weights were $20 \%$ heavier and $9 \%$ lighter, respectively, than the average were also removed to minimize individual differences in body weight. Then, 40 of 80 SAMP1 and 8 of 12 ICR mice with similar body weights were selected. The SAMP1 mice were randomly allocated to five groups, namely the control group, which was fed a control diet containing $5.5 \%$ fat $(\mathrm{w} / \mathrm{w}), 6 \% \mathrm{ca}-$ sein, $75.6 \%$ potato starch, $8.4 \%$ cellulose, $3.5 \%$ minerals, and $1 \%$ vitamins; the MFGM group, which was fed an MFGM diet consisting of the control diet supplemented with 1\% MFGM; the GTE group, which was fed a GTE diet consisting of the control diet supplemented with $0.5 \%$ GTE; the MFGMEx group, which was fed the MFGM diet and also given habitual exercise; and the GTEEx group, which was fed the GTE diet and also given habitual exercise ( $n=8$ per group).

ICR mice, which had previously been used as a control strain for comparison with SAMP1 were used as normally aging mice. The ICR mice were used as normally aging mice and were fed the control diet $(n=8)$. For 20 wk (from 23 to 43 wk of age), the mice were allowed ad libitum access to water and one of the following powdered diets: the control diet (control and ICR groups) or each experimental diet with or without exercise (MFGM, MFGMEx, GTE, and GTEEx groups). All mice were individually housed in regular plastic cages (TP-106; $175 \times$
$245 \times 125 \mathrm{~mm}$, Toyoriko, Tokyo, Japan), each of which had a nest box (Shepherd Specialty Papers, Watertown, $\mathrm{TN})$ to reduce stress. The cages of habitual exercise group had a running wheel (SW-15 mg; MELQUEST, Toyama, Japan), whereas those of the non-habitual-exercise groups did not. Dietary intake was measured throughout the experimental period by subtracting the remaining food weight from the initial weight of the food given on the previous feeding day. All animal experiments were conducted in the Experimental Animal Facility of Kao Corporation R\&D Department. The study was approved by the Animal Care Committee of the Kao Tochigi Institute. All experiments strictly followed the guidelines of that committee.

\section{Cell culture and mechanical stretching by using cyclic strain}

Murine C2C12 myoblasts (EC91031101) were obtained from the European Collection of Cell Cultures (Dainippon Sumitomo Pharma Biomedical, Osaka, Japan). The cells were plated onto flexible-bottomed plates (Bioflex Plates Collagen 1, Flexcell International Corp., Hillsborough, NC) coated with $1 \mathrm{mg} / \mathrm{mL}$ poly-L-lysine (Sigma-Aldrich Japan, Tokyo, Japan) and fibronectin (1:100, SigmaAldrich Japan) and maintained in an atmosphere of $95 \%$ air $-5 \% \mathrm{CO}_{2}$ at $37^{\circ} \mathrm{C}$ in Dulbecco's modified eagle medium (DMEM) supplemented with $10 \%$ fetal bovine serum and $10 \mathrm{ml} / \mathrm{L}$ Antibiotic-Antimycotic mixture (Gibco, Grand Island, NY). For differentiation into myotubes, $\mathrm{C} 2 \mathrm{C} 12$ myoblasts were grown to subconfluence on the plates; the culture medium was then replaced with DMEM containing 2\% heat-inactivated horse serum (Gibco) supplemented or not supplemented with $0.01 \%$ MFGM, $0.001 \%$ or $0.005 \%$ PLF, SLF, or sphingomyelin. During differentiation, the cells were subjected to cyclic equibiaxial stretching consisting of $10 \%$ elongation at $0.5 \mathrm{~Hz}$, with $1 \mathrm{~h}$ on and $5 \mathrm{~h}$ off for $72 \mathrm{~h}$, by using a Flexcell FX-5000 Tension System (Flexcell International Corp.), as described previously (Zhang et al. 2007). The culture media were replaced with fresh media once a day. At the end of $72 \mathrm{~h}$, the cells were washed with ice-cold phosphate-buffered saline once, homogenized with a QIAshredder (Qiagen K.K., Tokyo, Japan), and subjected to RNA extraction. Total RNA was extracted from frozen samples $(n=6)$ by using an RNeasy Mini kit (Qiagen K.K.) in accordance with the manufacturer's instructions.

\section{Blood and tissue collection}

Whole blood was collected from mice at the age of 43 wk in the non-fasting condition via the post-caval vein under anesthesia with inhaled sevoflurane (SEVOFRAN ${ }^{\circ}$; Maruishi Pharmaceutical Co., Ltd., Osaka, Japan). The blood was then immediately analyzed. The remaining 
blood was maintained at $4^{\circ} \mathrm{C}$ until plasma preparation. Immediately after euthanasia by exsanguination, the quadriceps, gastrocnemius, plantaris, extensor digitorum longus (EDL), and soleus muscles, along with the epididymal, perirenal, and retroperitoneal white adipose tissues (WAT) and the liver, were removed and weighed. Tissue samples were stored at $-80^{\circ} \mathrm{C}$ until analysis.

\section{Biochemical analysis}

The concentrations of erythrocytes, leukocytes, and platelets, along with hemoglobin concentration and the hematocrit, were measured in heparinized blood with an automatic hematocytometer (Celltac MEK-5258; Nihon Kohden, Tokyo, Japan). Plasma was obtained from the blood by centrifugation at $3500 \times g$ for $15 \mathrm{~min}$. Plasma glucose; triglycerides (TG); non-esterified fatty acid (NEFAs); aspartate aminotransferases (AST); alanine aminotransferase (ALT); total-cholesterol; lactate; lactate dehydrogenase (LDH); and ketone bodies were quantified by using N-A Glu-UL, N-A L TG-H, NEFAHA, N-A L GOT, N-A L GPT, N-A L T-CHO-H, N-A L LAC, N-A L LDH, and T-KB-H assay kits (Nittobo Medical Co., Ltd., Tokyo, Japan), respectively. Plasma insulin-like growth factor (IGF)-1 was measured with a mouse IGF-1 immunoassay (R\&D Systems Inc., Minneapolis, $\mathrm{MN})$. Plasma adiponectin levels were measured with a mouse/rat adiponectin ELISA kit (Otsuka Pharmaceuticals Co. Ltd, Tokyo, Japan). All measurements were performed in accordance with the manufacturers' instructions.

\section{Force of soleus and EDL muscle contractions induced by electrical stimulation}

Muscle force measurements were performed as described previously (Haramizu et al. 2011a, 2011b). The muscle of the right leg was quickly isolated. The muscle was anchored horizontally between two hooks-one fixed and one attached to an isometric force transducer (World Precision Instruments, Inc., Sarasota, FL)-and immersed in Krebs solution of the following composition: $119.7 \mathrm{mM}$ $\mathrm{NaCl}$, $4.5 \mathrm{mM} \mathrm{KCl}, 0.5 \mathrm{mM} \mathrm{MgCl} 2,0.7 \mathrm{mM} \mathrm{Na}_{2} \mathrm{HPO}_{4}$, $1.5 \mathrm{mM} \mathrm{NaH}_{2} \mathrm{PO}_{4}, 15 \mathrm{mM} \mathrm{NaHCO}_{3}, 2.5 \mathrm{mM} \mathrm{CaCl}_{2}$, and $10 \mathrm{mM}$ D-glucose; $\mathrm{pH} 7.3 \pm 0.1$. The solution was continuously bubbled with $95 \% \mathrm{O}_{2}-5 \% \mathrm{CO}_{2}$ at $37^{\circ} \mathrm{C}$. The muscle was electrically stimulated with a stimulus-isolation unit (SEN-3301; Nihon Kohden, Japan) and the optimal twitch length was set. Twitch force was measured with a single pulse; tetanic responses were induced with a $0.2-\mathrm{ms}$ pulse $(140 \mathrm{~Hz})$ for $330 \mathrm{~ms}$ once every $2 \mathrm{~s}$ and digitally recorded for 2 min with a bridge amplifier and data acquisition system (Quad-16I; World Precision Instruments, Inc.). Measurements were analyzed with Data-Trax software (World Precision Instruments, Inc.).

\section{Indirect calorimetry}

To elucidate the effect of MFGM or GTE with or without exercise on energy metabolism, we measured the oxygen consumption $\left(\mathrm{VO}_{2}\right)$ and respiratory quotient (RQ) of the mice after 17 to $18 \mathrm{wk}$ of feeding. We used an indirect calorimetric system equipped with a sixteenchamber airtight metabolic cage (ARCO2000-RAT/ANI 16 Chamber System; Arcosystem Inc., Chiba, Japan) (Murase et al. 2011). Each mouse was placed in a chamber for $3 \mathrm{~d}$ and allowed to acclimate to the surroundings before the measurement. Oxygen consumption and carbon dioxide production were then measured under feeding conditions for $24 \mathrm{~h}$. RQ was calculated by dividing the measured values of carbon dioxide production by those of oxygen consumption. During the measurement, locomotor activity was measured with an automated motion analysis system (Actracer2000; Arcosystem Inc.), which detects the amount of centroid fluctuation by using a weighted transducer.

\section{DNA microarray analysis}

Total RNA was extracted from frozen quadriceps muscle $(\mathrm{n}=4)$ by using an RNeasy Fibrous Tissue Mini kit (Qiagen K.K., Tokyo, Japan) in accordance with the manufacturer's instructions. For microarray analysis, the quality of total RNA samples was checked with an Agilent 2100 BioAnalyzer (Agilent Technologies Inc, Tokyo, Japan); the RNA integrity number of each sample was over 7.0. DNA microarray analysis was performed with a one-color system and the Agilent Mouse SurePrint G3 mouse gene expression array. In brief, $200 \mathrm{ng}$ of each RNA was labeled and amplified with a Low Input Quick Amp Labeling Kit (one color; Agilent Technologies) in accordance with manufacturer's instructions. Cyanine 3-labeled cRNA was fragmented and hybridized by using a Gene Expression Hybridization Kit and then washed with a Gene Expression Wash Pack (both Agilent Technologies). The hybridized microarray slides were scanned with an Agilent Technologies Microarray Scanner (Agilent Technologies) and the data were extracted by using Agilent Feature Extraction 10.7.1 in Hokkaido-System Science (Sapporo, Japan). After we had confirmed the high degree of reliability of the microarray processes on the basis of the QC report, data normalization and filtering were performed with GeneSpring GX 11.5 (Agilent technologies), as follows: 1) threshold raw signals were set to 1.0.; 2) 75th percentile normalization was used for the normalization algorithm; 3) the baseline was transformed to the median of all samples; and 4) raw values filtered by signal intensity value (upper cut-off: $100^{\text {th }}$ percentile; lower cut-off: $20^{\text {th }}$ percentile) of raw values and flagging to exclude absent reads. Probe sets were then identified by using unpaired $t$-test $(P<0.05)$ to compare between the experimental and control SAMP1 groups, with a relative fold-change value 
of $>1.2$ and no correction for multiple testing; this was done because the MicroArray Quality Control Consortium suggests the use of a fold-change cut off along with a non-stringent $P$-value cut-off as a baseline practice to improve reproducibility in microarray data processing (MAQC Consortium et al. 2006). Selected probe sets were analyzed with IPA (Ingenuity Pathways Analysis) software version 9.0 (Ingenuity Systems, Redwood City, CA).

\section{Quantitative real-time polymerase chain reaction (RT-PCR)} The microarray expression results were verified by using quantitative RT-PCR. The quadriceps muscles of mice in all groups ( $\mathrm{n}=7$ or 8 ) were analyzed for gene expression as described previously (Haramizu et al. 2011a, 2011b). The following mouse-specific primer sequences were used for the mRNAs for the following proteins: docking protein (Dok)-7 forward, TGAGCTTCCTGTTTGACT GCA; Dok-7 reverse, GCAACACGCTCTTCTGAGGC; muscle skeletal receptor-tyrosine kinase (MuSK) forward, CATGGCAGAGTTTGACAACCC; MuSK reverse, TTC GGAGGAACTCATTGAGGTC; neural cell adhesion molecule (NCAM) forward, CAGTGACCACGTCATGCTC AAG; NCAM reverse, CCTGAACACAAAGTGAGCTGC C; myogenic differentiation (MyoD)-1; CTAGATCCAGC CCCAAAGAAAG, MyoD reverse, AGGTGCAGCCAG AGTGCAA; myogenin forward, GCACTGGAGTTCGGT CCCA; and myogenin reverse, GTGATGCTGTCCACG ATGGA. For quantitative precision, the same amount of total RNA was consistently used for each expression analysis. Expression of each gene was normalized against that of the housekeeping gene encoding ribosomal protein, large, P0 (RPLP0/36B4).

\section{Western blot analysis}

Quadriceps muscles were homogenized and lysed on ice in a Physcotron homogenizer (Microtech, Chiba, Japan) and a ready-made homogenization buffer, CelLytic MT Mammalian Tissue Lysis/Extraction Reagent (Sigma, St Louis, MO) containing a protease inhibitor cocktail (Sigma), and phosphatase inhibitor cocktail-1 and -2 (Sigma). After centrifugation of the muscle mixtures at $12,000 \times g$ for $15 \mathrm{~min}$ at $4^{\circ} \mathrm{C}$, the supernatants were removed and their protein concentrations determined with a BCA protein assay kit (Pierce, Rockford, IL). Equal amounts of protein $(1 \mu \mathrm{g} / \mu \mathrm{L})$ were boiled at $100^{\circ} \mathrm{C}$ for $5 \mathrm{~min}$ in SDS sample buffer (Novagen, Inc., Madison, WI) and centrifuged at $2400 \times g$ for $5 \mathrm{~min}$ at $4^{\circ} \mathrm{C}$. The protein extracts were separated by sodium dodecyl sulfate polyacrylamide gel electrophoresis (SDS-PAGE) and transferred to Immobilon-P polyvinylidene fluoride (PVDF) membranes (Millipore Corp., Bedford, MA) at $200 \mathrm{~mA}$ for $1.5 \mathrm{~h}$. The membranes were then blocked with PVDF
Blocking Reagent for Can Get Signal (Toyobo Co., Ltd., Osaka, Japan) at room temperature for $1 \mathrm{~h}$ and incubated overnight with anti-Dok-7 (1:1000 dilution, Abcam, Cambridge, UK) and anti-MuSK (R\&D Systems Inc., Minneapolis, $\mathrm{MN}$ ) or anti- $\alpha$-tubulin (1:1000 dilution, Cell Signaling, Beverly, MA) primary antibodies in Immunoreaction Enhancer Solution 1 (Toyobo). After being washed four times with Tris-buffered saline containing 0.05\% Tween 20 (Bio-Rad Laboratories, Hercules, CA), the membranes were incubated with horseradish-peroxidaselabeled anti-rabbit (Cell Signaling) immunoglobulin for Dok-7 and $\alpha$-tubulin or anti-goat immunoglobulin for MuSK (Wako, Osaka, Japan) in Immunoreaction Enhancer Solution 2 (Toyobo). The blots were visualized with an ECL Prime Western Blotting Detection System (GE Healthcare, Buckinghamshire, UK) and a ChemiDoc XRS imaging system (Bio-Rad).

\section{Statistical analysis}

All values are presented as means \pm standard error (SE). Unpaired Student's $t$-tests after a preliminary F-test of the homogeneity of within-group variance were used to compare values between groups. When more than two groups were compared, statistical analysis was conducted with one-way ANOVA followed by Fisher's protected least significant difference or Dunnett's post-hoc tests (Statview for Windows version 5.0, SAS Institute Inc., Cary, NC). A $P$ value of less than 0.05 was considered statistically significant.

\section{Results}

Effect of exercise plus MFGM on body and tissue weights in SAMP1

Body and tissue weights of mice at the age of 43 wk are shown in Table 1. The quadriceps, gastrocnemius, plantaris, EDL and soleus muscles in the control SAMP1 group weighed significantly less than those in the ICR group. In contrast, the epididymal, perirenal, and retroperitoneal WAT tissues were significantly heavier in the control SAMP1 group than in the ICR group. The quadriceps muscle weighed significantly more in the MFGMEx mice than in the control SAMP1 group, whereas the weights of the gastrocnemius, plantaris, EDL and soleus muscles were similar between the groups. The GTE and GTEEx groups had significantly lower body weights than the control SAMP1 group. Fat and liver weights were significantly lower in both the GTE and the GTEEx group than in the control SAMP1, whereas muscle weight did not differ between the groups. Dietary intake was significantly higher in the ICR group than in the control SAMP1 group, but body weights did not differ between the ICR mice and the control SAMP1. 
Table 1 Body weight, feed intakes, feed efficiency, and tissues weights

\begin{tabular}{|c|c|c|c|c|c|c|}
\hline \multirow{3}{*}{ 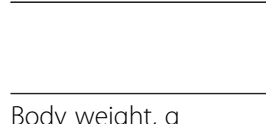 } & \multirow{2}{*}{ ICR } & \multirow[t]{2}{*}{ Control } & \multirow[t]{2}{*}{ MFGM } & \multirow[t]{2}{*}{ MFGMEx } & \multirow[t]{2}{*}{ GTE } & \multirow[t]{2}{*}{ GTEEX } \\
\hline & & & & & & \\
\hline & $44.2 \pm 1.4$ & $42.2 \pm 2.7$ & $42.2 \pm 1.7$ & $40.3 \pm 1.6$ & $29.6 \pm 1.9^{*}$ & $32.5 \pm 1.0^{*}$ \\
\hline Dietary intake, $\mathrm{g}$ & $791.0 \pm 26.2^{*}$ & $584.7 \pm 13.9^{\text {fキ }}$ & $564.1 \pm 8.5$ & $632.6 \pm 24.8$ & $527.5 \pm 3.8$ & $569.8 \pm 4.1$ \\
\hline Quadriceps, mg & $424.6 \pm 13.0^{*}$ & $318.0 \pm 6.0^{\text {fキ }}$ & $306.3 \pm 6.4$ & $355.8 \pm 8.5^{*}$ & $301.1 \pm 16.8$ & $323.9 \pm 11.5$ \\
\hline Gastrocnemius, mg & $328.8 \pm 14.1^{*}$ & $228.8 \pm 7.6^{\text {抽 }}$ & $222.4 \pm 5.5$ & $234.3 \pm 5.8$ & $198.5 \pm 12.3$ & $238.2 \pm 16.7$ \\
\hline Plantaris, mg & $44.5 \pm 2.7^{*}$ & $27.3 \pm 1.8^{\neq \neq}$ & $28.5 \pm 2.6$ & $29.5 \pm 2.2$ & $25.6 \pm 2.5$ & $27.8 \pm 1.9$ \\
\hline $\mathrm{EDL}, \mathrm{mg}$ & $27.6 \pm 0.8^{*}$ & $20.4 \pm 0.8^{\text {丰 }}$ & $19.2 \pm 1.4$ & $19.9 \pm 0.9$ & $19.1 \pm 0.4$ & $18.4 \pm 1.4$ \\
\hline Soleus, mg & $20.1 \pm 1.3^{*}$ & $15.6 \pm 0.8^{\dagger}$ & $17.1 \pm 0.8$ & $17.1 \pm 1.1$ & $15.4 \pm 1.3$ & $16.6 \pm 1.2$ \\
\hline Epididymal fat, $\mathrm{g}$ & $1.43 \pm 0.13^{*}$ & $2.34 \pm 0.22^{+t}$ & $2.48 \pm 0.15$ & $2.31 \pm 0.22$ & $1.11 \pm 0.31^{*}$ & $1.29 \pm 0.25^{*}$ \\
\hline Perirenal fat, $g$ & $0.19 \pm 0.03^{*}$ & $0.37 \pm 0.07^{\dagger}$ & $0.33 \pm 0.05$ & $0.26 \pm 0.03$ & $0.11 \pm 0.03^{*}$ & $0.15 \pm 0.02^{*}$ \\
\hline Retroperitoneal fat, $\mathrm{g}$ & $0.37 \pm 0.03$ & $0.56 \pm 0.07^{+}$ & $0.58 \pm 0.05$ & $0.46 \pm 0.04$ & $0.22 \pm 0.06^{*}$ & $0.23 \pm 0.06^{*}$ \\
\hline Liver, g & $1.39 \pm 0.08$ & $1.36 \pm 0.07$ & $1.36 \pm 0.04$ & $1.27 \pm 0.03$ & $1.09 \pm 0.03^{*}$ & $1.09 \pm 0.03^{*}$ \\
\hline
\end{tabular}

Values are means \pm S.E. of 7 or 8 mice.

${ }^{\dagger} P<0.05,{ }^{\dagger \dagger} P<0.01,{ }^{+\dagger} P<0.001,{ }^{\neq \neq} P<0.0001$, significant difference between ICR group and control SAMP1 group at the age of 43 wk by unpaired $t$-test.

${ }^{*} P<0.05$, significant difference vs. control SAMP1 group at the age of 43 wk by Dunnett's test.

\section{Effect of exercise plus MFGM on blood and plasma components in SAMP1}

The blood level of erythrocytes, as well as the hemoglobin, and hematocrit values, was significantly lower in the control SAMP1 group than in the ICR group at the age of
43 wk (Table 2). The hemoglobin and hematocrit values were significantly higher in the MFGMEx group than in the control SAMP1 group. We measured plasma adiponectin and IGF-1 levels, because they play important roles in regulating energy metabolism (Kahn et al. 2005)

Table 2 Blood and plasma analysis

\begin{tabular}{|c|c|c|c|c|c|c|}
\hline & \multirow[t]{2}{*}{ ICR } & \multirow[t]{2}{*}{ Control } & \multirow[t]{2}{*}{ MFGM } & MFGMEx & \multirow[t]{2}{*}{ GTE } & \multirow[t]{2}{*}{ GTEEx } \\
\hline & & & & SAMP1 & & \\
\hline \multicolumn{7}{|l|}{ Blood component } \\
\hline $\mathrm{WBC}, 10^{2} / \mu \mathrm{L}$ & $46.4 \pm 13.6$ & $38.7 \pm 8.1$ & $34.4 \pm 4.7$ & $28.5 \pm 4.6$ & $41.3 \pm 13.7$ & $32.8 \pm 9.3$ \\
\hline $\mathrm{RBC}, 10^{4} / \mu \mathrm{L}$ & $844.4 \pm 19.8^{*}$ & $730.1 \pm 21.7^{\dagger+}$ & $771.6 \pm 16.7$ & $779.5 \pm 19.7$ & $675.0 \pm 27.9$ & $696.2 \pm 55.6$ \\
\hline Haemoglobin, mg/dL & $13.8 \pm 0.2^{*}$ & $12.3 \pm 0.3^{+\dagger}$ & $12.7 \pm 0.2$ & $13.5 \pm 0.3^{*}$ & $11.5 \pm 0.4$ & $12.3 \pm 0.2$ \\
\hline Haematocrit,\% & $43.2 \pm 0.8^{*}$ & $37.0 \pm 1.0^{\ddagger}$ & $38.8 \pm 0.8$ & $40.3 \pm 1.1^{*}$ & $35.1 \pm 1.1$ & $36.4 \pm 2.1$ \\
\hline Platelet, $10^{4} / \mu \mathrm{L}$ & $93.0 \pm 6.4$ & $73.9 \pm 2.8^{\dagger}$ & $76.6 \pm 3.4$ & $72.8 \pm 9.0$ & $93.2 \pm 11.2$ & $72.6 \pm 4.5$ \\
\hline \multicolumn{7}{|l|}{ Plasma component } \\
\hline Glucose, mg/dL & $210.8 \pm 18.5$ & $230.8 \pm 17.1$ & $217.2 \pm 5.7$ & $207.7 \pm 12.1$ & $219.9 \pm 26.7$ & $241.2 \pm 19.2$ \\
\hline Lactate, mg/dL & $55.0 \pm 5.1$ & $63.5 \pm 4.0$ & $56.2 \pm 4.3$ & $66.1 \pm 7.6$ & $68.0 \pm 10.3$ & $66.1 \pm 11.3$ \\
\hline $\mathrm{LDH}, \mathrm{IU} / \mathrm{L}$ & $287.4 \pm 34.8^{*}$ & $150.6 \pm 13.7^{\dagger+}$ & $158.7 \pm 7.8$ & $150.3 \pm 11.8$ & $171.3 \pm 19.3$ & $148.2 \pm 9.2$ \\
\hline AST, IU/L & $48.5 \pm 5.3^{*}$ & $28.4 \pm 1.3^{t \dagger}$ & $28.9 \pm 1.9$ & $28.1 \pm 2.7$ & $37.3 \pm 3.0$ & $33.8 \pm 2.0$ \\
\hline$A L T, I U / L$ & $15.7 \pm 0.8$ & $16.8 \pm 2.8$ & $18.6 \pm 1.8$ & $19.2 \pm 4.3$ & $14.2 \pm 2.1$ & $16.1 \pm 2.4$ \\
\hline Total Chol, mg/dL & $163.2 \pm 20.9$ & $170.7 \pm 6.8$ & $189.1 \pm 13.5$ & $188.9 \pm 11.0$ & $159.1 \pm 13.9$ & $160.2 \pm 11.8$ \\
\hline $\mathrm{TG}, \mathrm{mg} / \mathrm{dL}$ & $55.8 \pm 8.7$ & $88.5 \pm 7.4^{\dagger}$ & $104.7 \pm 19.4$ & $114.4 \pm 24.0$ & $82.6 \pm 11.7$ & $90.1 \pm 14.6$ \\
\hline Ketone body, mg/dL & $163.1 \pm 41.0$ & $248.8 \pm 30.0$ & $219.8 \pm 45.5$ & $242.6 \pm 55.8$ & $310.6 \pm 79.7$ & $329.4 \pm 86.5$ \\
\hline NEFA, mEq/L & $0.9 \pm 0.1$ & $1.0 \pm 0.1$ & $1.0 \pm 0.1$ & $1.1 \pm 0.1$ & $0.8 \pm 0.1$ & $1.0 \pm 0.1$ \\
\hline Adiponectin, pg/mL & $3.5 \pm 0.2^{*}$ & $2.0 \pm 0.1^{\text {㧊 }}$ & $2.0 \pm 0.1$ & $2.4 \pm 0.1$ & $2.0 \pm 0.2$ & $2.1 \pm 0.1$ \\
\hline IGF-1, ng/mL & $596.3 \pm 53.7^{*}$ & $474.2 \pm 14.1$ & $501.6 \pm 10.4$ & $549.2 \pm 26.9$ & $438.6 \pm 24.8$ & $426.8 \pm 25.9$ \\
\hline
\end{tabular}

Values are means \pm S.E. of 7 or 8 mice.

${ }^{\dagger} P<0.05,{ }^{+\dagger} P<0.01,{ }^{\neq \neq} P<0.0001$, significant difference between ICR group and control SAMP1 group at the age of 43 wk by unpaired $t$-test.

${ }^{*} P<0.05$, Significant difference vs. control SAMP1 group at the age of 43 wk by Dunnett's test. 
and protein synthesis in skeletal muscle (Perrini et al. 2010). The plasma adiponectin level was significantly lower $(P<0.05)$, and the plasma IGF-1 level tended to be lower $(P=0.07)$ in the control SAMP1 group than in the ICR group. The MFGMEx group had significantly higher plasma adiponectin and IGF-1 levels than did the control SAMP1 group. The control SAMP1 group had significantly lower plasma LDH and AST and significantly higher TG levels than did the ICR mice. These plasma measurements did not differ between the experimental groups and the control SAMP1 group.

Effect of exercise plus MFGM on tetanic contractile force of soleus and EDL muscles in SAMP1

The tetanic contractile force of the soleus (Figure 1A) and EDL (Figure 1B) muscles was significantly lower in the control SAMP1 group than in the ICR group at the age of 43 wk. The MFGMEx group had significantly higher
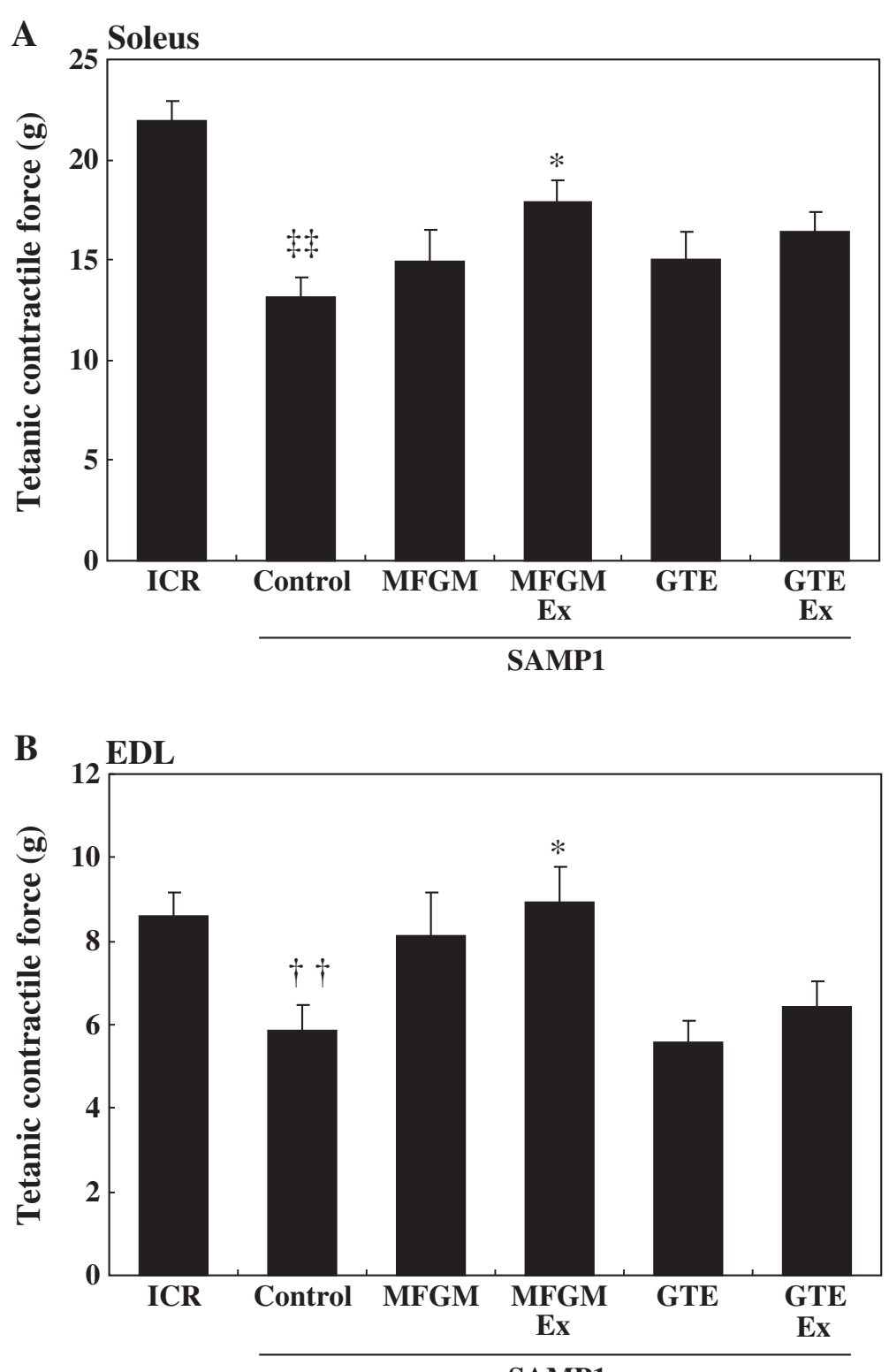

Figure 1 Effects of milk-fat globule membrane (MFGM) or green tea extract (GTE) on tetanic contractile force of soleus and extensor digitorum longus (EDL) muscles. The tetanic contractile force of the isolated soleus (A) and EDL (B) muscles was measured as described in the Methods. Values are means \pm S.E. of 7 or 8 mice. ${ }^{\dagger \dagger} P<0.01$ and ${ }^{\ddagger \neq} P<0.0001$, significant difference between ICR group and control SAMP1 group by unpaired $t$-test. ${ }^{*} P<0.05$, significant difference vs. the control SAMP1 group by Dunnett's posthoc test. MFGMEx, MFGM plus habitual exercise; GTEEx, GTE plus habitual exercise. 
tetanic contractile force than the control SAMP1 group in the soleus (Figure 1A) and EDL (Figure 1B) muscles. Contractile force in the GTEEx group did not differ significantly from that in the control SAMP1 group.

\section{Effect of exercise plus MFGM on locomotor activity and energy metabolism in SAMP1}

Spontaneous locomotor activity and $\mathrm{VO}_{2}$ were significantly lower in the control SAMP1 group than in the ICR group at the age of $40-41 \mathrm{wk}(P<0.05$; Table 3$)$. In contrast, the MFGMEx group had significantly higher spontaneous locomotor activity and $\mathrm{VO}_{2}$ than did the control SAMP1 group $(P<0.05)$. Oxygen consumption did not differ between GTE-fed mice (GTE and GTEEx groups) and the control SAMP1 mice. There were no differences in RQ between the experimental groups.

Effects of exercise plus MFGM on muscle gene expression To identify the potential molecular mechanisms underlying the beneficial effects of habitual exercise combined with dietary MFGM on muscle mass and force, we compared the transcriptomic profile in the quadriceps muscle between the MFGMEx and the control SAMP1 groups. In the microarray analyses, probe sets identified as differentially expressed between the groups had a relative fold change value of $>1.2$ with no correction for multiple testing. Volcano plot analysis in GeneSpring revealed that 893 probes were differentially expressed in the MFGMEx group compared with the control SAMP1 group. Among these 893 probes, 317 were identified as up-regulated and 576 probes were downregulated (Additional file 1: Table S1). IPA was then used to decipher the biological processes characterized by the list differentially expressed probes. The biological processes highly represented in the MFGMEx group compared with the control SAMP1 group were "nervous system development and function" ( $P=3.35 \mathrm{E}-05$ to 2.25E-02), "hematological system development and function" ( $P=1.59 \mathrm{E}-04$ to $2.30 \mathrm{E}-02)$, "immune cell trafficking" ( $P=1.59 \mathrm{E}-04$ to $2.30 \mathrm{E}-02)$, "lymphoid tissue structure and development" ( $P=1.59 \mathrm{E}-04$ to $2.25 \mathrm{E}-02)$, and "embryonic development" ( $P=5.04 \mathrm{E}-04$ to $2.25 \mathrm{E}-02)$ within the hierarchy "physiological systems development and functions." The top five functional annotations in the most significant process are shown in Table 4. The most significant function responding to the combination of habitual exercise and dietary MFGM was "formation of synapse," followed by "growth of neurites" and "development of neuromuscular junction." In contrast, the microarray analysis followed by the IPA analysis of the GTEEx and control SAMP1 groups showed that the most significant function responding to the combination of habitual exercise and dietary GTE was "hematological system development and function." These functions by habitual exercise and dietary MFGM were not observed in response to combination of habitual exercise and dietary GTE (data not shown).

\section{Effects of exercise plus MFGM on expression of genes encoding IGF-1 signaling molecules}

To explore the differences in muscle weight between the SAMP1 controls and the ICR controls and (in the case of the quadriceps) between the MFGMEx group and the SAMP1 controls, the genes involved in muscle development were assessed by using RT-PCR. The control SAMP1 group had significantly lower igflr and higher IGF-1 binding protein (igfbp)-5 gene expression (18.8\% and 32.2\%, respectively) than the ICR group. IGF-1 mRNA expression level did not differ among the groups (Figure 2). The MFGMEx group had significantly higher igfir and lower igfbp5 gene expression (by $23.4 \%$ and $24.3 \%$, respectively) than did the control SAMP1 group.

\section{Effect of exercise plus MFGM on MuSK and Dok-7}

In light of the microarray results, the genes involved in "nervous system development and function" were examined. Microarray analysis revealed that habitual exercise plus dietary MFGM significantly increased MuSK mRNA expression (Additional file 1: Table S1). Because MuSK and Dok-7 are crucial for NMJ formation (DeChiara et al. 1996; Inoue et al. 2009; Okada et al. 2006), we measured Dok-7 mRNA expression; our microarray analysis found only one instance in which the gene tended to be upregulated.

Expression of mRNAs for MyoD $(+37.7 \%)$ and myogenin (+63.6\%) was significantly higher in the MFGMEx group than in the control SAMP1 group (Figure 3), whereas it was significantly lower in the control SAMP1

Table 3 Energy metabolism and spontaneous activity

\begin{tabular}{lcccccc}
\hline & ICR & Control & MFGM & MFGMEx & GTE & GTEEx \\
& & & & SAMP1 & \\
\hline Activity, g* & & & $115.99 \pm 15.51$ & $171.21 \pm 25.17^{*}$ & $72.28 \pm 9.45$ & $135.36 \pm 16.34$ \\
$\mathrm{VO}_{2}, \mathrm{ml} / \mathrm{min}$ & $154.11 \pm 18.69$ & $92.02 \pm 16.75^{\dagger}$ & $2.18 \pm 0.09$ & $2.45 \pm 0.06^{*}$ & $1.82 \pm 0.10$ & $2.03 \pm 0.07$ \\
$\mathrm{RQ}$ & $2.48 \pm 0.09^{*}$ & $2.10 \pm 0.10^{\dagger}$ & $0.835 \pm 0.021$ & $0.855 \pm 0.022$ & $0.838 \pm 0.024$ & $0.794 \pm 0.016$ \\
\hline
\end{tabular}

Values are means \pm S.E. of 7 or 8 mice.

${ }^{+} P<0.05$, significant difference between ICR group and control SAMP1 group at the age of $40-41$ wk by unpaired $t$-test.

${ }^{*} P<0.05$, significant difference vs. control SAMP1 group at the age of 43 wk by Dunnett's test. 
Table 4 "Nervous System Development and Function" characterised by differentilly expressed probes in the quadriceps muscles of the control and MFGMEx groups, as determined by using IPA (Ingenuity Pathways Analysis) software v9.0

\begin{tabular}{lcc}
\hline Functional annotation & $\begin{array}{c}\text { Differentially expressed } \\
\text { genes/total genes }\end{array}$ & $P$-value \\
\hline Formation of synapse & $8 / 179$ & $3.33 \mathrm{E}-05$ \\
Growth of neurites & $18 / 708$ & $1.89 \mathrm{E}-03$ \\
$\begin{array}{l}\text { Development of neuromuscular } \\
\text { junction }\end{array}$ & $4 / 37$ & $2.54 \mathrm{E}-03$ \\
Outgrowth of neurites & $15 / 614$ & $6.53 \mathrm{E}-03$ \\
Morphogenesis of neurites & $7 / 438$ & $1.58 \mathrm{E}-02$ \\
\hline
\end{tabular}

group than in the ICR group. The MFGMEx group had significantly higher MuSK mRNA expression $(+26.9 \%)$ than the control SAMP1 group, whereas MuSK mRNA expression did not differ between the ICR group and the control SAMP1 group. The MFGMEx group had significantly higher NCAM mRNA expression $(+29.5 \%)$ than did the control SAMP1 group; these results were consistent with the microarray results. Whereas Dok-7 was not found in the microarray results (Additional file 1: Table S1), our RT-PCR analysis showed that the MFGMEx group had significantly greater Dok-7 $(+31.0 \%)$ mRNA expression than the control SAMP1 group (Figure 3).

The Dok-7 protein level was significantly higher $(+30.8 \%$, $P<0.01$ ), and the MuSK protein level tended to be higher $(+18.2 \%, P=0.1)$, in the MFGMEx group than in the control SAMP1 group (Figure 4). ICR mice had significantly more MuSK protein than the control SAMP1 mice. The Dok-7 protein level did not differ between these two groups.

Effects of MFGM, PLF, SLF, and sphingomyelin plus mechanical stretching on expression of genes encoding Dok-7, MuSK, and myogenin in differentiating $\mathrm{C} 2 \mathrm{C} 12$ cells Skeletal muscle is highly adaptable and responds to exercise and training, thus increasing muscle mass and function. To further understand the mechanisms underlying
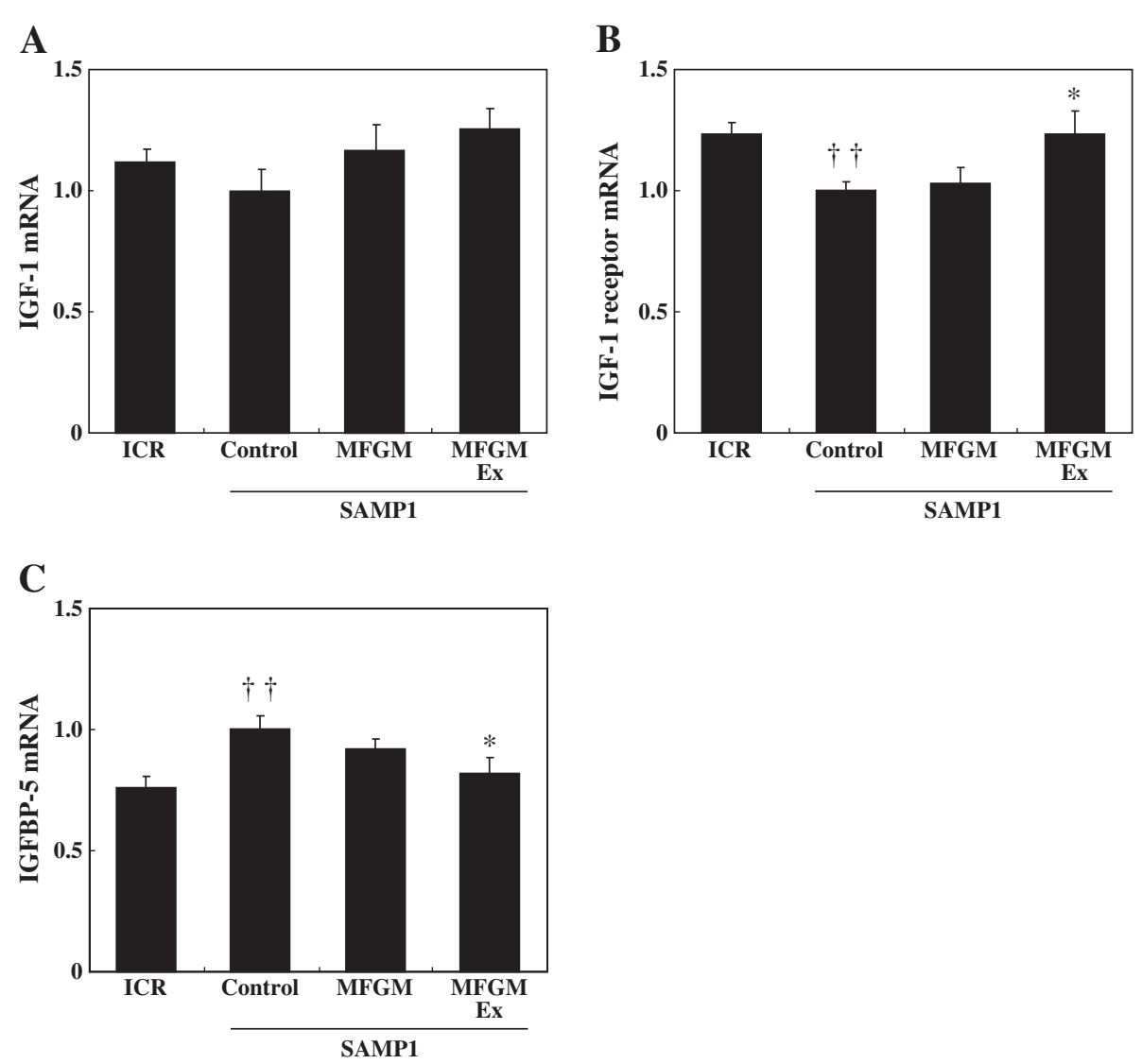

Figure 2 Effects of milk-fat globule membrane (MFGM) on expression of genes associated with insulin-like growth factor (IGF)-1 signaling-related molecules. mRNA expression levels of IGF-1 (A), IGF-1 receptor (B), and IGF-binding protein (IGFBP)-5 (C) were measured using quantitative real-time PCR. Values are means \pm S.E. of 7 or 8 mice. ${ }^{\dagger \dagger} P<0.01$, significant difference between ICR group and control SAMP1 group by unpaired $t$-test. ${ }^{*} P<0.05$, significant difference vs. control SAMP1 group by Fisher's PLSD posthoc test. Values are expressed as ratios, using the value of the control SAMP1 group as 1.0. MFGMEx, MFGM plus habitual exercise. 


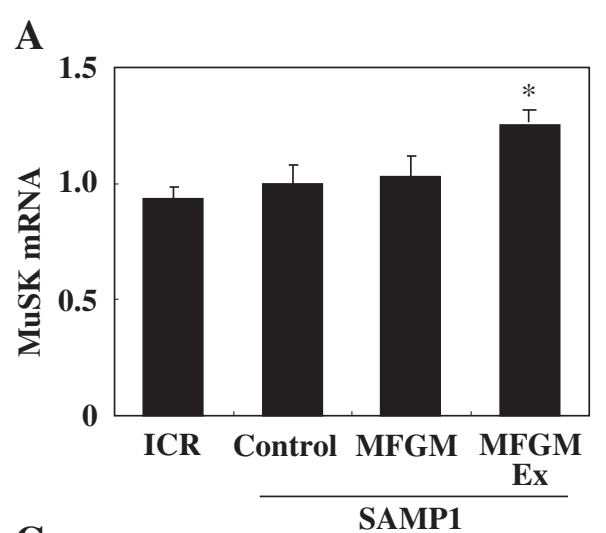

C

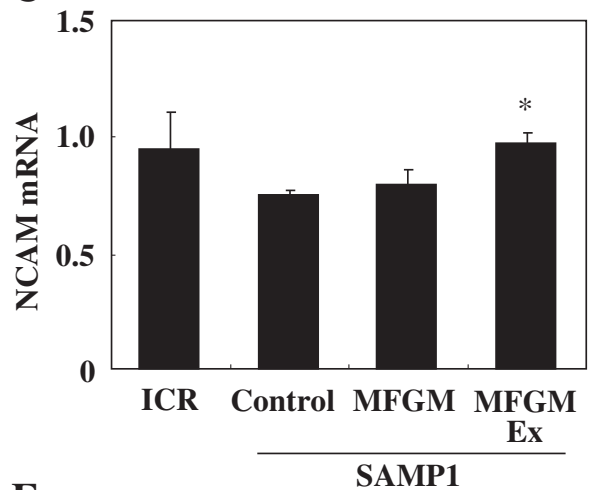

$\mathbf{E}$

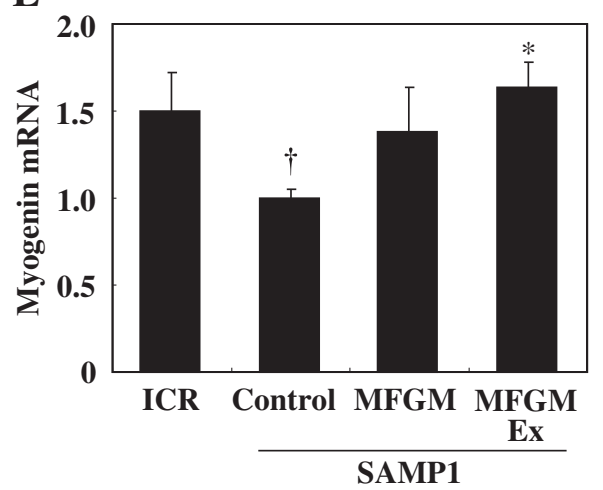

B

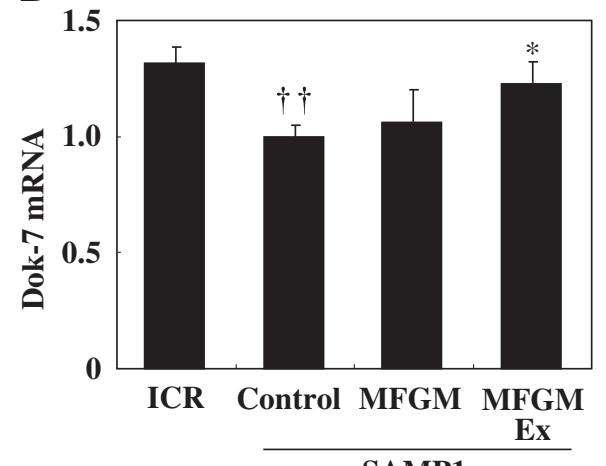

D

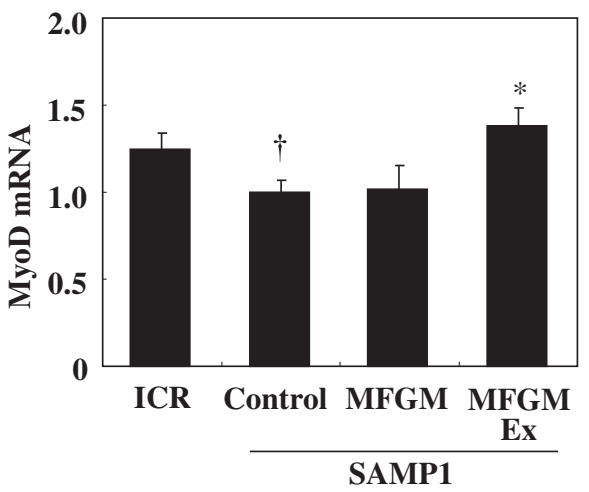

Figure 3 Effects of milk-fat globule membrane (MFGM) on expression of genes associated with nervous system development and function-related molecules. mRNA expression levels of MuSK (A), Dok-7 (B), NCAM (C), MyoD (D), and myogenin (E) were measured using quantitative real-time PCR. Expression of each gene was normalized against that of the housekeeping gene encoding ribosomal protein, large, PO (RPLP0/36B4). Values are means \pm S.E. of 7 or 8 mice. ${ }^{\dagger \dagger} P<0.01$ and ${ }^{\dagger} P<0.05$, significant difference between ICR group and control SAMP1 group by unpaired $t$-test. ${ }^{*} P<0.05$, significant difference vs. control SAMP1 group by Fisher's PLSD posthoc test. Values are expressed as ratios, using the value of the control SAMP1 group as 1.0. MuSK, muscle skeletal receptor-tyrosine kinase; Dok-7, docking protein-7; NCAM, neural cell adhesion molecule; MyoD, myogenic differentiation; MFGMEx, MFGM plus habitual exercise.

the adaptive response of skeletal muscles in vivo, in vitro culture systems that use mechanical stretching of cultured myotubes have been developed to mimic in vivo muscle physiology (Passey et al. 2011), including neuromuscular adaptation in response to exercise (Folland and Williams 2007; Hubatsch and Jasmin 1997; Jasmin et al. 1991; Sveistrup et al. 1995). Accordingly, we examined the effects of MFGM-derived fractions and sphingomyelin combined with mechanical stretch (as a substitute for exercise in vivo) on the expression of several genes.

Treatment of the stretched cells with MFGM, PLF, SLF, or sphingomyelin significantly increased Dok-7 gene expression compared with that in cells that received mechanical stretching alone; this was evident especially in the cells treated with SLF or sphingomyelin (Figure 5). Myogenin gene expression was increased significantly by 


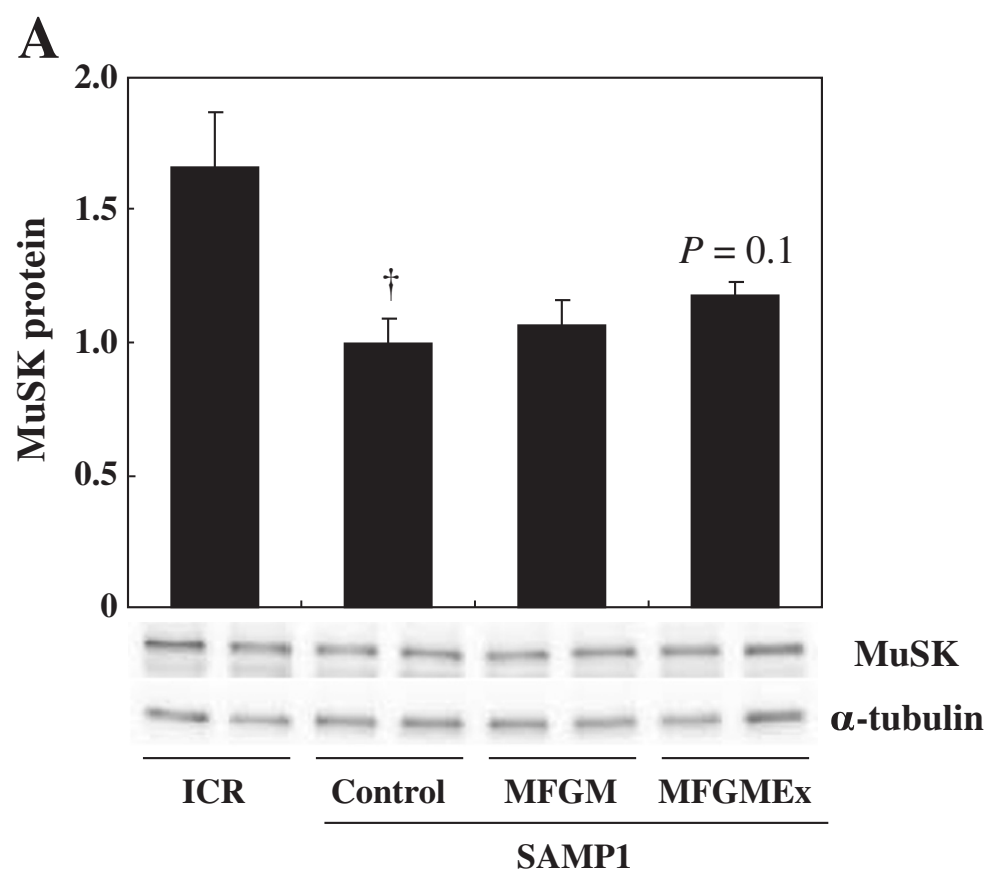

B

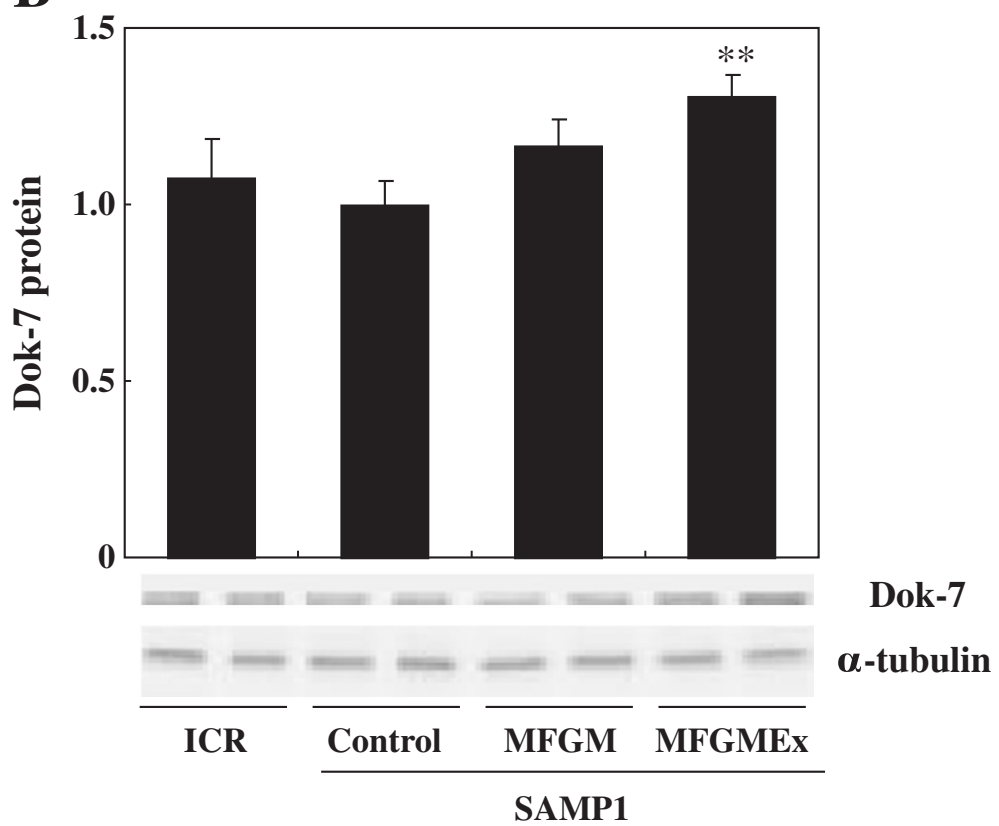

Figure 4 Effects of milk-fat globule membrane (MFGM) on production of MuSK and Dok-7 proteins. Levels of production of the proteins MuSK (A), and Dok-7 (B) were measured by western blot analysis. The quadriceps muscle was removed from each mouse in the non-fasting, resting condition. Tissue lysates were then prepared and subjected to western blot analysis. Values are means \pm S.E. of 7 or 8 mice. ${ }^{\dagger} P<0.05$, significant difference between ICR group and control SAMP1 group by unpaired $t$-test. ${ }^{* *} P<0.01$, significant difference vs. Control SAMP1 group by Fisher's PLSD posthoc test. Values are expressed as ratios, using the value of the control SAMP1 group as 1.0. MFGMEx, MFGM plus habitual exercise.

treatment with $0.01 \%$ MFGM or with $0.001 \%$ or $0.005 \%$ PLF fraction plus mechanical stretching of the cells. These results are consistent with the effects of the combination of habitual exercise and dietary MFGM observed in vivo.

\section{Discussion}

Our major finding was that habitual exercise combined with nutritional supplementation in the form of dietary MFGM, but not exercise plus dietary GTE, attenuated 

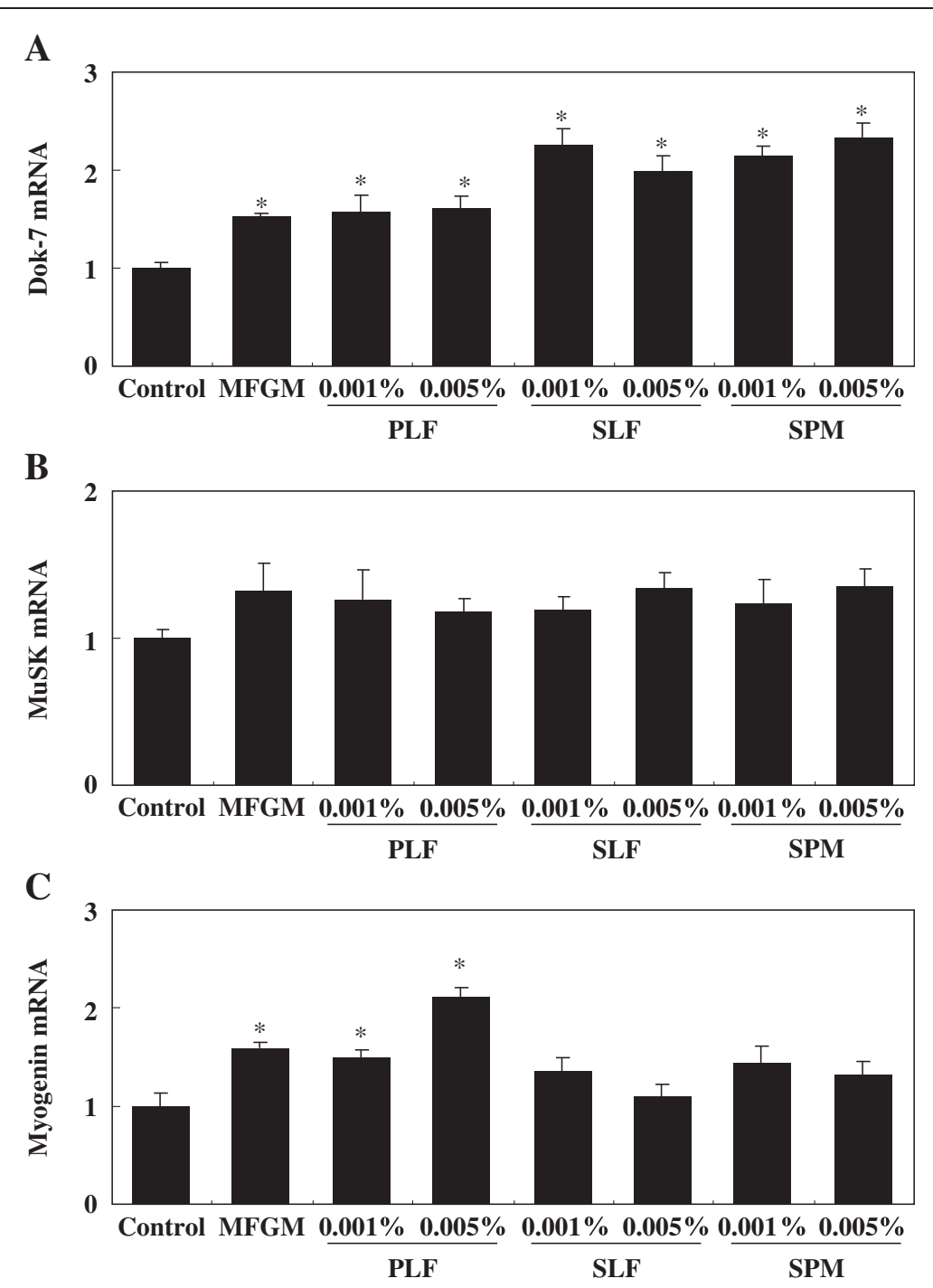

Figure 5 Effects of milk-fat globule membrane (MFGM), the phospholipid fraction (PLF), the sphingolipid fraction (SLF), and sphingomyelin (SPM), plus mechanical stretching, on expression of the mRNAs of Dok-7, MuSK, and myogenin in differentiating C2C12 cells. Levels of expression of the mRNAs of Dok-7 (A), MuSK (B), and myogenin (C) were measured by using quantitative real-time PCR. Expression of each gene was normalized against that of the housekeeping gene encoding ribosomal protein, large, PO (RPLP0/36B4). Values are means \pm S.E. of 6 samples. ${ }^{*} P<0.05$, significant difference vs. control group by Dunnett's posthoc test. Values are expressed as ratios, using the value of the control group as 1.0.

age-related loss of muscle mass and maximum contractile force in SAMP1; this result may have been due to the increase in metabolic rate and physical activity. Our results also suggest that the beneficial effects of habitual exercise plus dietary MFGM on skeletal muscle mass and function are related to the stimulation of neuromuscular system development and function.

The control SAMP1 group had smaller muscle mass and contractile force production than did ICR mice. These results were consistent with those of Sakakima et al. (2004) and with our previous finding that contractile force in the soleus muscle was significantly lower in SAMP1 mice than in SAMR1 mice (Haramizu et al. 2011a, 2011b). We used ICR mice as normal group of controls; our results suggest that, in comparison with these mice, SAMP1 mice exhibit aging-related deterioration in the mass and function of both soleus and EDL muscle. SAMP1 mice were less active either locomotively or metabolically; this may have been the cause of the increase in WAT accumulation and plasma TG levels, and the decrease in adiponectin levels, compared with those in ICR mice.

Even though we consider ICR mice to be valid controls for SAMP1 mice (Lee et al. 2013; Nagano et al. 2000; Sakakima et al. 2004), we cannot rule out the possibility that the observed differences in the results obtained with ICR and SAMP1 mice may be due to differences between the strains. Because Derave et al. (2005) stated 
that SAMR1 mice were not suitable because of difficulties in breeding them, and because we have had problems with tumors of the oral cavity in SAMR1 mice, we prefer to use ICR mice as controls for SAMP1 mice in our studies.

Our SAMP1 mice had significantly lower skeletal muscle mass than did ICR mice at age 43 wks. Considering the fact that there is no difference in the ratio of gastrocnemius muscle weight to body weight between ICR and SAMP1 mice at the age of 24 wk (Sakakima et al. 2004), the lower muscle mass in SAMP1 in this study is not likely to be caused by arrested muscle growth but by sarcopenia. Our previous study showed that the reduced muscle mass in SAMP1 could be explained partly by a decrease in IGF-1 signaling, which dynamically regulates muscle protein synthesis (Haramizu et al. 2011a, 2011b). IGF-1 receptor gene deletion in muscle causes earlier postnatal diabetes and mortality (Kitamura et al. 2003). Expression of the gene encoding IGFBP (binding protein)-5, decreases with age (Welle et al. 2001); IGFBP-5 is produced by muscle cells and suppresses muscle differentiation by interfering with IGF-1-dependent signaling (Mukherjee et al. 2008). We found that decreased expression of the mRNA for IGF1 receptor and increased expression of the mRNA for IGFBP-5 mRNA expression, either of which can interfere with IGF-1 signaling, seemed to be associated with decreased mass of the quadriceps muscle in SAMP1.

Most interestingly, the aging-associated deteriorations in muscle mass and force were significantly attenuated by a combination of habitual exercise and dietary MFGM. Aging-dependent declines in serum IGF-1 levels may also contribute to loss of muscle mass (Perrini et al. 2010); a recent study has shown that loss of muscle mass in aged mice can be attenuated partly by increasing serum IGF-1 levels by feeding royal jelly (Niu et al. 2013). Therefore, the increases in serum IGF-1 and IGF-1 receptor mRNA levels and decreases in IGFBP-5 mRNA levels after habitual exercise plus dietary MFGM might have contributed to the increase in muscle mass and contractile force production in SAMP1.

SAMP1 had lower concentrations of circulating erythrocytes, and lower hemoglobin and hematocrit levels than did ICR mice, in parallel with previous findings that with advancing age these levels decline (Boggs and Patrene 1986; Coppola et al. 2000). Concurrently, the decreased erythrocytes and hemoglobin levels reduce the oxygencarrying capacity of the blood (Tsai et al. 2010); this may be consistent with the lower oxygen consumption in SAMP1 in the present study. MFGM intake combined with exercise increased hemoglobin and hematocrit levels and tended to increase the RBC count in the SAMP1 mice; this may have resulted in increased oxygen consumption. The protective effect of habitual exercise plus dietary
MFGM on erythrocytes (including their survival, synthesis, and degradation) needs to be elucidated. Here, we did not measure mitochondrial and oxidative enzyme activities. In our previous studies, the lower physical performance of SAMP1 mice has been associated with a decrease in muscle $\beta$-oxidation capacity and in the mRNA expression levels of cytochrome c oxidase and peroxisome proliferator-activated receptor-gamma coactivator1 (Haramizu et al. 2011a, 2011b; Murase et al. 2008). Therefore, we cannot rule out the possibility that a decrease in muscle mitochondrial activity for processing oxygen is also responsible for the lower whole-body oxygen consumption in SAMP1 mice.

Plasma adiponectin levels were lower in SAMP1 than in ICR mice but increased after MFGM intake plus habitual exercise. Adiponectin stimulates energy metabolism in skeletal muscle through the action of AMP-activated protein kinase (Kahn et al. 2005), and the absence of adiponectin causes muscle dysfunction (Krause et al. 2008). Therefore, our results suggest that an increase in plasma adiponectin levels also contributes to the increase in muscle force and whole-body energy expenditure seen with MFGM intake plus exercise. Bouassida et al. (2010) have shown that both acute and regular exercise increase circulating adiponectin levels. However, increase in adiponectin levels was observed by exercise plus GTE. Therefore, the results seem to be related more to the effect of exercise plus MFGM than of exercise alone.

Of more interest is our finding that the major effect of habitual exercise plus dietary MFGM was characterized in our transcriptomic analysis as 'nervous system development.' A combination of habitual exercise and dietary MFGM increased the levels of MuSK and Dok-7, both of which play essential roles in synapse formation at the NMJ because lacking MuSK or Dok-7 failed to form NMJ formation (DeChiara et al. 1996; Inoue et al. 2009; Okada et al. 2006), suggesting that exercise plus MFGM may help to improve NMJ formation. A combination of habitual exercise and dietary MFGM also increased the levels of expression of the mRNAs for MyoD and myogenin. The increased levels of expression of the mRNAs for MyoD and myogenin after exercise plus MFGM may help to improve NMJ formation and thereby improve muscle contractile function, because lack of MyoD expression results in aberrant development of neuromuscular synapses, leading to muscle contractile dysfunction (Macharia et al. 2010). In addition, MyoD and myogenin are associated with muscle differentiation (Capkovic et al. 2008). Therefore, increased expression of the genes encoding MyoD and myogenin may also contribute to increased neural or muscle adaptation (i.e., through an in the number of myonuclei), or both, after habitual exercise plus dietary MFGM. 
In contrast to our findings, some studies have found that the expression of some genes (e.g., encoding those encoding myogenin and NCAM) increases in denervation or aging (Ibebunjo et al. 2013; Larkin et al. 2003; Moresi et al. 2010). Although we cannot dismiss the difference between our findings and these previous ones, it is possible that the muscle of our SAMP1 at the age of $43 \mathrm{wk}$, unlike those in these previous models of severe aging and denervation, did not in fact undergo severe denervation. Therefore, the decreased levels of mRNAs for myogenin and NCAM in our SAMP1 mice might not have been associated with muscle denervation. Similarly, considering our finding that quadriceps muscle mass and soleus force was significantly increased by exercise plus MFGM in SAMP1, the increased levels of myogenin and NCAM mRNA expression seen with exercise plus MFGM do not suggest the presence of muscle denervation. However, more detailed analyses, for example by histological and molecular approaches, are needed to translate the transcriptional changes that we found here into improved muscle mass, function, and metabolism after a combination of habitual exercise and daily consumption of MFGM.

Our study had some limitations. First, since we did not count the rotations of the running wheel consistently during the experimental period, we cannot rule out the possibility that a combination of habitual exercise plus dietary MFGM increased total physical activity and thus affected muscle physiology. However, our preliminary study showed that dietary supplementation with 1\% MFGM did not change spontaneous activity in mice (data not shown). Therefore, we speculate that the beneficial effects of exercise plus MFGM are not the result of a change in spontaneous activity levels.

Second, because we did not include a group subjected to habitual exercise alone, the effects on muscle mass, function, and NMJ formation may have been the result of exercise alone. A numbers of studies have shown that voluntary exercise alone in an unloaded condition (treadmill running and spontaneous wheel running) fails to improve muscle mass and strength (Ishihara et al. 1998; Gallo et al. 2006; Legerlotz et al. 2008); considering that resistance training is effective in improving muscle mass and strength (Chalé et al. 2013; Leenders et al. 2013), voluntary exercise may be difficult in managing muscle mass and strength when used alone. Consistent with this point, habitual running alone and dietary supplementation with green tea catechins combined with habitual running did not improve muscle mass (Murase et al. 2008). Here, habitual exercise plus dietary GTE did not change either muscle mass, or function, or the expression of NMJ-associated genes. In addition, the combination of mechanical stretch plus MFGM supplementation, but not mechanical stretch alone, increased the expression of genes involved in muscle differentiation and NMJ formation (Figure 5); this was consistent with the effects of habitual exercise plus dietary MFGM in vivo. Taking the results together enables us to conclude that the beneficial effects of the combination of habitual exercise and dietary MFGM are produced by the interaction between habitual exercise and dietary MFGM, and are unlikely to be produced by habitual exercise alone. Nevertheless, further studies are required to clarify the mechanism underlying these effects of combined habitual exercise and dietary MFGM.

Consumption of whole milk by young adults after resistance training promotes muscle protein synthesis and inhibits protein breakdown, leading to improved net muscle protein balance (Elliot et al. 2006; Josse et al. 2010; Wilkinson et al. 2007). Moreover, a cohort study has revealed that muscle strength in community-dwelling elderly is affected by the type of milk feeding in infancy (Robinson et al. 2012). The beneficial effects of milk on muscle mass and function are thought to be due to its nutritional capacity as a good source of proteins, lipids, amino acids, vitamins, and minerals. Cantó et al. (2012) have shown that nicotinamide riboside (the $\mathrm{NAD}^{+}$precursor found in milk) activates sirtuin activity, enhances mitochondrial gene expression, and prevents diet-induced obesity. We demonstrated here that MFGM may also be a beneficial component of milk that, when combined with habitual exercise, suppresses aging-associated deterioration of muscle mass and strength and loss of NMJ formation. Studies are in progress to clarify the clinical efficacy of dietary supplementation with MFGM combined with regular exercise in human adults including the elderly.

We found here that while myogenin mRNA expression was upregulated by MFGM-derived phospholipids, Dok7 mRNA expression was upregulated by MFGM-derived phospholipids and sphingolipids, and by milk-derived sphingomyelin in differentiating myoblasts under mechanical stretch, suggesting that the beneficial effects of habitual exercise plus dietary MFGM in vivo are at least partly due to these components. Lipids play crucial roles in various cellular functions. For example, phosphatidylserine is involved in myoblast fusion (van den Eijnde et al. 2001) and phosphatidylcholine triggers IGF-1-stimulated responses (Rauch and Loughna 2005). Moreover, sphingomyelin levels in the plasma membrane, a reservoir of bioactive sphingolipids, decrease during muscle satellite cell activation (Nagata et al. 2006), and increased levels of sphingosine-1phosphate and sphingosine (metabolites of sphingomyelin) individually attenuate fatigue-induced decline in muscle contractile force (Danieli-Betto et al. 2005). In our preliminary experiment in rats, MFGM ingestion increased the contents of phospholipids, sphingolipids, free fatty acids, and triglycerides in the mesenteric lymph, suggesting that dietary MFGM is absorbed and circulates after being metabolized into phospholipids and sphingolipids (our 
unpublished observation). Therefore, we speculate that phospholipids and sphingolipids contribute to a mechanism by which MFGM combined with habitual exercise improves muscle function. However, further studies are required to elucidate the effects of this combination in vivo.

\section{Conclusions}

Our findings provide evidence that, in senescenceaccelerated mice, a combination of habitual exercise and dietary supplementation with MFGM improves agerelated deficits in muscle function by improving neuromuscular development and IGF-1 signaling. Further studies are needed to clarify the mechanism underlying the interaction between regular exercise and dietary MFGM.

\section{Additional file}

Additional file 1: Table S1. Probe names that were increased or decreased by MFGM intake combined with exercise in the quadriceps muscle.

\section{Abbreviations}

MFGM: Milk fat globule membrane (MFGM); GTE: Green tea extract; SAMP1: Senescence-accelerated P1 mice; Dok-7: Docking protein-7; NMJ: Neuromuscular junction; SAMR: Senescence-accelerated resistant mouse; PLF: Phospholipid fraction; TLC: Thin-layer chromatography; SLF: Sphingolipid fraction; DMEM: Dulbecco's modified eagle medium; EDL: Extensor digitorum longus; WAT: White adipose tissues; TG: Triglycerides; NEFA: Non-esterified fatty acid; AST: Aspartate aminotransferases; ALT: Alanine aminotransferase; HDL: High-density lipoprotein; LDL: Low-density lipoprotein; LDH: Lactate dehydrogenase; IGF: Insulin-like growth factor; $\mathrm{VO}_{2}$ : Oxygen consumption; RQ: Respiratory quotient; MuSK: Muscle skeletal receptor-tyrosine kinase; NCAM: Neural cell adhesion molecule; MyoD: Myogenic differentiation; RPLP0/36B4: Ribosomal protein, large, P0; PVDF: Immobilon-P polyvinylidene fluoride; SDS-page: Sodium dodecyl sulfate polyacrylamide gel electrophoresis; SE: Standard error; ANOVA: Analysis of variance; IGFBP: IGF-binding protein.

\section{Competing interests}

All authors are employees of the Kao Corporation. The Kao Corporation is the sole funder of the research presented in this study. All authors and the Kao Corporation have filed patents to which the outcome of this research is relevant (US8268360).

\section{Authors' contribution}

$\mathrm{SH}, \mathrm{NO}$ and AS managed the study, analyzed the data, and drafted the manuscript. SH, MY, KH, AO, and TM were involved in the experiments and in collection and analysis of the data. SH, NO, TH and AS was involved in the conception of the study, management of research expenses, and interpretation of data. Design of the study and critical revision of the manuscript were undertaken by all authors. All authors read and approved the final manuscript.

\section{Authors' information}

Satoshi Haramizu is a research scientist at the R\&D - Biological Science Research of Kao Corporation. Mr. Haramizu's research focus is nutritional and exercise physiology for health.

Takuya Mori is a research scientist at the R\&D - Biological Science Research of Kao Corporation. Mr. Mori's research focus is on nutritional physiology for health. Michiko Yano, PhD, is a research scientist at the R\&D - Biological Science Research of Kao Corporation. Dr. Yano's research focus is on muscle biology for health. Noriyasu Ota, is a principal research scientist at the R\&D - Biological Science Research of Kao Corporation. Mr. Ota's research focus is on nutritional and exercise physiology for health.
Kohjiro Hashizume is a research scientist at the R\&D - Biological Science Research of Kao Corporation. Mr. Hashizume's research focus is on organic chemistry for finding beneficial food compositions.

Atsuko Otsuka is a research scientist at the R\&D - Biological Science Research of Kao Corporation. Mrs. Otsuka's research focus is on muscle biology for health. Tadashi Hase DVM is a Vice-President with responsibility for the R\&D - Biological Science Research of Kao Corporation. Dr. Hase's research focus is on lipid metabolism, nutrition, and health science.

Akira Shimotoyodome, PhD, is a Director for the R\&D - Biological Science Research of Kao Corporation. Dr. Shimotoyodome's research focus is on lipid metabolism, nutrition, and health science

\section{Acknowledgements}

We thank Satoko Soga and Yukiko Horigane for their technical assistance, and Naoko Ojima for her secretarial assistance.

Received: 24 January 2014 Accepted: 26 March 2014

Published: 4 July 2014

\section{References}

Balice-Gordon RJ (1997) Age-related changes in neuromuscular innervation. Muscle Nerve Suppl 5:S83-587

Boggs DR, Patrene K (1986) Hematopoiesis and aging. V. A decline in hematocrit occurs in all aging female B6D2F1 mice. Exp Aging Res 12:131-134

Bouassida A, Chamari K, Zaouali M, Feki Y, Zbidi A, Tabka Z (2010) Review on leptin and adiponectin responses and adaptations to acute and chronic exercise. Br J Sports Med 44:620-630

Breen L, Phillips SM (2011) Skeletal muscle protein metabolism in the elderly: Interventions to counteract the 'anabolic resistance' of ageing. Nutr Metab (Lond) 8:68

Cantó C, Houtkooper RH, Pirinen E, Youn DY, Oosterveer MH, Cen Y, FernandezMarcos PJ, Yamamoto H, Andreux PA, Cettour-Rose P, Gademann K, Rinsch C, Schoonjans K, Sauve AA, Auwerx J (2012) The NAD(+) precursor nicotinamide riboside enhances oxidative metabolism and protects against high-fat diet-induced obesity. Cell Metab 15:838-847

Capkovic KL, Stevenson S, Johnson MC, Thelen JJ, Cornelison DD (2008) Neural cell adhesion molecule (NCAM) marks adult myogenic cells committed to differentiation. Exp Cell Res 314:1553-1565

Cavaletto M, Giuffrida MG, Conti A (2008) Milk fat globule membrane components-a proteomic approach. Adv Exp Med Biol 606:129-141

Chai RJ, Vukovic J, Dunlop S, Grounds MD, Shavlakadze T (2011) Striking denervation of neuromuscular junctions without lumbar motoneuron loss in geriatric mouse muscle. PLoS One 6:e28090

Chalé A, Cloutier GJ, Hau C, Phillips EM, Dallal GE, Fielding RA (2013) Efficacy of whey protein supplementation on resistance exercise-induced changes in lean mass, muscle strength, and physical function in mobility-limited older adults. J Gerontol A Biol Sci Med Sci 68:682-690

Coppola L, Caserta F, De Lucia D, Guastafierro S, Grassia A, Coppola A, Marfella R, Varricchio M (2000) Blood viscosity and aging. Arch Gerontol Geriatr 31:35-42

Danieli-Betto D, Germinario E, Esposito A, Megighian A, Midrio M, Ravara B, Damiani E, Libera LD, Sabbadini RA, Betto R (2005) Sphingosine 1-phosphate protects mouse extensor digitorum longus skeletal muscle during fatigue. Am J Physiol Cell Physiol 288:C1367-C1373

DeChiara TM, Bowen DC, Valenzuela DM, Simmons MV, Poueymirou WT, Thomas S, Kinetz E, Compton DL, Rojas E, Park JS, Smith C, DiStefano PS, Glass DJ, Burden SJ, Yancopoulos GD (1996) The receptor tyrosine kinase MuSK is required for neuromuscular junction formation in vivo. Cell 85:501-512

Derave W, Eijnde BO, Ramaekers M, Hespel P (2005) Soleus muscles of SAMP8 mice provide an accelerated model of skeletal muscle senescence. Exp Gerontol 40:562-572

Elliot TA, Cree MG, Sanford AP, Wolfe RR, Tipton KD (2006) Milk ingestion stimulates net muscle protein synthesis following resistance exercise. Med Sci Sports Exerc 38:667-674

Folland JP, Williams AG (2007) The adaptations to strength training: morphological and neurological contributions to increased strength. Sports Med 37:145-168

Gallo M, Gordon T, Syrotuik D, Shu Y, Tyreman N, MacLean I, Kenwell Z, Putman $C T$ (2006) Effects of long-term creatine feeding and running on isometric functional measures and myosin heavy chain content of rat skeletal muscles. Pflugers Arch 452:744-755 
Haramizu S, Ota N, Hase T, Murase T (2011a) Catechins attenuate eccentric exercise-induced inflammation and loss of force production in muscle in senescence-accelerated mice. J Appl Physiol 111:1654-1663

Haramizu S, Ota N, Hase T, Murase T (2011b) Aging-associated changes in physical performance and energy metabolism in the senescence-accelerated mouse. J Gerontol A Biol Sci Med Sci 66:646-655

Hosokawa M (2002) A higher oxidative status accelerates senescence and aggravates age-dependent disorders in SAMP strains of mice. Mech Ageing Dev 123:1553-1561

Hubatsch DA, Jasmin BJ (1997) Mechanical stimulation increases expression of acetylcholinesterase in cultured myotubes. Am J Physiol Cell Physiol 273:C2002-C2009

Ibebunjo C, Chick JM, Kendall T, Eash JK, Li C, Zhang Y, Vickers C, Wu Z, Clarke BA, Shi J, Cruz J, Fournier B, Brachat S, Gutzwiller S, Ma Q, Markovits J, Broome M, Steinkrauss M, Skuba E, Galarneau JR, Gygi SP, Glass DJ (2013) Genomic and proteomic profiling reveals reduced mitochondrial function and disruption of the neuromuscular junction driving rat sarcopenia. Mol Cell Biol 33:194-212

Inoue A, Setoguchi K, Matsubara Y, Okada K, Sato N, Iwakura Y, Higuchi O, Yamanashi Y (2009) Dok-7 activates the muscle receptor kinase MuSK and shapes synapse formation. Sci Signal 2:ra7

Ishihara A, Roy RR, Ohira Y, Ibata Y, Edgerton VR (1998) Hypertrophy of rat plantaris muscle fibers after voluntary running with increasing loads. J Appl Physiol 84:2183-2189

Janssen I, Shepard DS, Katzmarzyk PT, Roubenoff R (2004) The healthcare costs of sarcopenia in the United States. J Am Geriatr Soc 52:80-85

Jasmin BJ, Gardiner PF, VI G (1991) Muscle acetylcholinesterase adapts to compensatory overload by a general increase in its molecular forms. J Appl Physiol 70:2485-2489

Josse AR, Tang JE, Tarnopolsky MA, Phillips SM (2010) Body composition and strength changes in women with milk and resistance exercise. Med Sci Sports Exerc 42:1122-1130

Kadhiresan VA, Hassett CA, Faulkner JA (1996) Properties of single motor units in medial gastrocnemius muscles of adult and old rats. J Physiol 493:543-552

Kahn BB, Alquier T, Carling D, Hardie DG (2005) AMP-activated protein kinase: ancient energy gauge provides clues to modern understanding of metabolism. Cell Metab 1:15-25

Kitamura T, Kahn CR, Accili D (2003) Insulin receptor knockout mice. Annu Rev Physiol 65:313-332

Krause MP, Liu Y, Vu V, Chan L, Xu A, Riddell MC, Sweeney G, Hawke TJ (2008) Adiponectin is expressed by skeletal muscle fibers and influences muscle phenotype and function. Am J Physiol Cell Physiol 295:C203-C212

Larkin LM, Kuzon WM, Halter JB (2003) Effects of age and nerve-repair grafts on reinnervation and fiber type distribution of rat medial gastrocnemius muscles. Mech Ageing Dev 124(5):653-661

Larsson L (1995) Motor units: remodeling in aged animals. J Gerontol A Biol Sci Med Sci 50:91-95

Lee YJ, Jeong BH, Choi EK, Carp Rl, Kim YS (2013) Complete genome sequences of new xenotropic murine leukemia viruses from the senescence-accelerated mouse (SAM): molecular and phylogenetic analyses. PLoS One 8:e55669

Leenders $M$, Verdijk LB, van der Hoeven L, van Kranenburg J, Nilwik R, van Loon $\sqcup J$ (2013) Elderly men and women benefit equally from prolonged resistance-type exercise training. J Gerontol A Biol Sci Med Sci 68:769-779

Legerlotz K, Elliott B, Guillemin B, Smith HK (2008) Voluntary resistance running wheel activity pattern and skeletal muscle growth in rats. Exp Physiol 93:754-762

Macharia R, Otto A, Valasek P, Patel K (2010) Neuromuscular junction morphology, fiber-type proportions, and satellite-cell proliferation rates are altered in MyoD(-/-) mice. Muscle Nerve 42:38-52

Manini TM, Clark BC (2012) Dynapenia and aging: an update. J Gerontol A Biol Sci Med Sci 67:28-40

MAQC Consortium, Shi L, Reid LH, Jones WD, Shippy R, Warrington JA, Baker SC, Collins PJ, de Longueville F, Kawasaki ES, Lee KY, Luo Y, Sun YA, Willey JC, Setterquist RA, Fischer GM, Tong W, Dragan YP, Dix DJ, Frueh FW, Goodsaid FM, Herman D, Jensen RV, Johnson CD, Lobenhofer EK, Puri RK, Schrf U, Thierry-Mieg J, Wang C, Wilson M et al (2006) The MicroArray Quality Control (MAQC) project shows inter- and intraplatform reproducibility of gene expression measurements. Nat Biotechnol 24:1151-1161

McGregor RA, Poppitt SD (2013) Milk protein for improved metabolic health: a review of the evidence. Nutr Metab (Lond) 10:46

Moresi V, Williams AH, Meadows E, Flynn JM, Potthoff MJ, McAnally J, Shelton JM, Backs J, Klein WH, Richardson JA, Bassel-Duby R, Olson EN (2010) Myogenin and class II HDACs control neurogenic muscle atrophy by inducing E3 ubiquitin ligases. Cell 143:35-45

Mukherjee A, Wilson EM, Rotwein P (2008) Insulin-like growth factor (IGF) binding protein-5 blocks skeletal muscle differentiation by inhibiting IGF actions. Mol Endocrinol 22:206-215

Murase T, Haramizu S, Shimotoyodome A, Nagasawa A, Tokimitsu I (2005) Green tea extract improves endurance capacity and increases muscle lipid oxidation in mice. Am J Physiol Regul Integr Comp Physiol 288:R708-R715

Murase T, Haramizu S, Shimotoyodome A, Tokimitsu I (2006a) Reduction of diet-induced obesity by a combination of tea-catechin intake and regular swimming. Int J Obes 30:561-568

Murase T, Haramizu S, Shimotoyodome A, Tokimitsu I, Hase T (2006b) Green tea extract improves running endurance in mice by stimulating lipid utilization during exercise. Am J Physiol Regul Integr Comp Physiol 290:R1550-R1556

Murase T, Haramizu S, Ota N, Hase T (2008) Tea catechin ingestion combined with habitual exercise suppresses the aging-associated decline in physical performance in senescence-accelerated mice. Am J Physiol Regul Integr Comp Physiol 295:R281-R289

Murase T, Misawa K, Minegishi Y, Aoki M, Ominami H, Suzuki Y, Shibuya Y, Hase T (2011) Coffee polyphenols suppress diet-induced body fat accumulation by downregulating SREBP-1C and related molecules in C57BL/6 J mice. Am J Physiol Endocrinol Metab 300:E122-E133

Nagano S, Matsunaga S, Takae R, Morimoto N, Suzuki S, Yoshida H (2000) Immunolocalization of transforming growth factor-betas and their receptors in the intervertebral disk of senescence-accelerated mouse. Int J Oncol 17:461-466

Nagata Y, Kobayashi H, Umeda M, Ohta N, Kawashima S, Zammit PS, Matsuda R (2006) Sphingomyelin levels in the plasma membrane correlate with the activation state of muscle satellite cells. J Histochem Cytochem 54:375-384

Niu K, Guo H, Guo Y, Ebihara S, Asada M, Ohrui T, Furukawa K, Ichinose M, Yanai K, Kudo Y, Arai H, Okazaki T, Nagatomi R (2013) Royal jelly prevents the progression of sarcopenia in aged mice in vivo and in vitro. J Gerontol A Biol Sci Med Sci 68:1482-1492

Okada K, Inoue A, Okada M, Kakuta S, Jigami T, Kubo S, Shiraishi H, Eguchi K, Motomura M, Akiyama T, Iwakura Y, Higuchi O, Yamanashi Y (2006) The muscle protein Dok-7 is essential for neuromuscular synaptogenesis. Science 312:1802-1805

Oshida K, Shimizu T, Takase M, Tamura Y, Shimizu T, Yamashiro Y (2003) Effects of dietary sphingomyelin on central nervous system myelination in developing rats. Pediatr Res 53:589-593

Passey S, Martin N, Player D, Lewis MP (2011) Stretching skeletal muscle in vitro: Does it replicate in vivo physiology? (Review). Biotechnol Lett 33:1513-1521

Perrini S, Laviola L, Carreira MC, Cignarelli A, Natalicchio A, Giorgino F (2010) The $\mathrm{GH} / \mathrm{IGF} 1$ axis and signaling pathways in the muscle and bone: mechanisms underlying age-related skeletal muscle wasting and osteoporosis. J Endocrinol 205:201-210

Rauch C, Loughna P (2005) C2C12 skeletal muscle cells exposure to phosphatidylcholine triggers IGF-1 like-responses. Cell Physiol Biochem 15:211-224 Robinson SM, Simmonds SJ, Jameson KA, Syddall HE, Dennison EM, Cooper C, Sayer AA (2012) Hertfordshire cohort study group. (2012) muscle strength in older community-dwelling men is related to type of milk feeding in infancy. J Gerontol A Biol Sci Med Sci 67:990-996

Rowan SL, Rygiel K, Purves-Smith FM, Solbak NM, Turnbull DM, Hepple RT (2012) Denervation causes fiber atrophy and myosin heavy chain co-expression in senescent skeletal muscle. PLoS One 7:e29082

Sakakima H, Yoshida Y, Suzuki S, Morimoto N (2004) The effects of aging and treadmill running on soleus and gastrocnemius muscle morphology in the senescence-accelerated mouse (SAMP1). J Gerontol A Biol Sci Med Sci 59:1015-1021

Shimotoyodome A, Haramizu S, Inaba M, Murase T, Tokimitsu I (2005) Exercise and green tea extract stimulate fat oxidation and prevent obesity in mice. Med Sci Sports Exerc 37:1884-1892

Sinha-Hikim I, Sinha-Hikim AP, Parveen M, Shen R, Goswami R, Tran P, Crum A, Norris KC (2013) Long-term supplementation with a cystine-based antioxidant delays loss of muscle mass in aging. J Gerontol A Biol Sci Med Sci 68:749-759

Sveistrup H, Chan RY, Jasmin BJ (1995) Chronic enhancement of neuromuscular activity increases acetylcholinesterase gene expression in skeletal muscle. Am J Physiol Cell Physiol 269:C856-C862

Takeda T (1999) Senescence-accelerated mouse (SAM): a biogerontological resource in aging research. Neurobiol Aging 20:105-110 
Takeda T, Hosokawa M, Takeshita S, Irino M, Higuchi K, Matsushita T, Tomita Y, Yasuhira K, Hamamoto H, Shimizu K, Ishii M, Yamamuro T (1981) A new murine model of accelerated senescence. Mech Ageing Dev 17:183-194

Takeda T, Hosokawa M, Higuchi K (1991) Senescence-accelerated mouse (SAM): a novel murine model of accelerated senescence. J Am Geriatr Soc 39:911-919

Takeda T, Matsushita T, Kurozumi M, Takemura K, Higuchi K, Hosokawa M (1997) Pathobiology of the senescence-accelerated mouse (SAM). Exp Gerontol 32:117-127

Tan LJ, Liu SL, Lei SF, Papasian CJ, Deng HW (2012) Molecular genetic studies of gene identification for sarcopenia. Hum Genet 131:1-31

Tsai AG, Hofmann A, Cabrales P, Intaglietta M (2010) Perfusion vs. oxygen delivery in transfusion with "fresh" and "old" red blood cells: the experimental evidence. Transfus Apher Sci 43:69-78

Valdez G, Tapia JC, Kang H, Clemenson GD Jr, Gage FH, Lichtman JW, Sanes JR (2010) Attenuation of age-related changes in mouse neuromuscular synapses by caloric restriction and exercise. Proc Natl Acad Sci U S A 107:14863-14868

van den Eijnde SM, van den Hoff MJ, Reutelingsperger CP, van Heerde WL, Henfling ME, Vermeij-Keers C, Schutte B, Borgers M, Ramaekers FC (2001) Transient expression of phosphatidylserine at cell-cell contact areas is required for myotube formation. J Cell Sci 114:3631-3642

Vesper H, Schmelz EM, Nikolova-Karakashian MN, Dillehay DL, Lynch DV, Merrill AH Jr (1999) Sphingolipids in food and the emerging importance of sphingolipids to nutrition. J Nutr 129:1239-1250

Welle S, Brooks A, Thornton CA (2001) Senescence-related changes in gene expression in muscle: similarities and differences between mice and men. Physiol Genomics 5:67-73

Wilkinson SB, Tarnopolsky MA, Macdonald MJ, Macdonald JR, Armstrong D, Phillips SM (2007) Consumption of fluid skim milk promotes greater muscle protein accretion after resistance exercise than does consumption of an isonitrogenous and isoenergetic soy-protein beverage. Am J Clin Nutr 85:1031-1040

Zhang SJ, Truskey GA, Kraus WE (2007) Effect of cyclic stretch on beta1D-integrin expression and activation of FAK and RhoA. Am J Physiol Cell Physiol 292: C2057-C2069

doi:10.1186/2193-1801-3-339

Cite this article as: Haramizu et al: Habitual exercise plus dietary supplementation with milk fat globule membrane improves muscle function deficits via neuromuscular development in senescence-accelerated mice. SpringerPlus 2014 3:339.

\section{Submit your manuscript to a SpringerOpen ${ }^{\circ}$ journal and benefit from:}

- Convenient online submission

- Rigorous peer review

- Immediate publication on acceptance

- Open access: articles freely available online

- High visibility within the field

- Retaining the copyright to your article

Submit your next manuscript at $\gg$ springeropen.com 